Synthesis of the Aluminophosphate ICP-1 by Self-Assembly of 1,3-

Diphenylguanidine: Insights into Supramolecular Aggregation

Teresa Álvaro-Muñoz, Ana B. Pinar, Dubravka Šišak, Joaquín PérezPariente, and Luis Gómez-Hortigüela*

http://dx.doi.org/10.1021/jp500026d

J. Phys. Chem. C 2014, 118, 4835-4845 


\title{
Synthesis of the Aluminophosphate ICP-1 by Self-Assembly of 1,3-Diphenylguanidine: Insights into Supramolecular Ag- gregation
}

\author{
Teresa Álvaro-Muñoz ${ }^{\dagger}$, Ana B. Pinar ${ }^{\ddagger}$, Dubravka Šišak ${ }^{\ddagger}$, Joaquín Pérez-Pariente ${ }^{\dagger}$ and Luis Gómez- \\ Hortigüela ${ }^{\dagger, *}$ \\ ${ }^{\dagger}$ Instituto de Catálisis y Petroleoquímica, ICP-CSIC. C/ Marie Curie 2, 28049. Madrid, Spain. \\ ${ }^{*}$ Laboratory of Crystallography, ETH Zurich, CH-8093 Zurich, Zurich, Switzerland.
}

\begin{abstract}
Diphenylguanidine (DPG) has distinguishable polar and apolar groups, aromatic rings that can self-assemble through $\pi-\pi$ type interactions, and high conformational flexibility. These features make it a potential self-assembling structuredirecting agent in the synthesis of hybrid host-guest aluminophosphates. Computational simulations show that the molecule has a strong tendency to self-assemble in aqueous solution. Large supramolecular organic aggregates are produced, with the hydrophobic aromatic rings located in the center of the aggregates, stabilized by $\pi-\pi$ type interactions, and the hydrophilic guanidine groups on the external surface in close contact with water molecules. With this organic molecule, a new 1-D AlPO framework material (ICP1) was formed. Its structure, characterized by a combination of single-crystal and powder diffraction techniques, consists of $\mathrm{AlP}_{2} \mathrm{O}_{8} \mathrm{H}$ chains connected to the polar groups of the organic DPG molecules through a complex $\mathrm{H}$-bonding network. This material has an extremely high organic content, close to that of typical mesoporous materials. However, DPG molecules are part of the ICP1 network, rather than guest molecules in the pores, so removal of DPG results in a collapse of a structure, limiting its potential applications. Nevertheless, this work demonstrates the potential of using self-assembling organic molecules for producing very open-framework materials.
\end{abstract}

KEYWORDS. Aluminophosphate, Aggregation, Supramolecular, Self-assembly, Diphenylguanidine, Molecular simulations, Zeolites, Rietveld refinement, ICP-1

\section{INTRODUCTION}

Zeolites, and more generally nanoporous materials, are traditionally used in ion-exchange processes, separations and catalysis, but nowadays they are also applied in other fields of material science. Their regular microscopic pore structures and the associated properties can be exploited in all fields of molecular recognition phenomena.

The aluminophosphate family of zeotypes $\left(\mathrm{AlPO}_{4}-n\right.$ series), in which the network is composed of $\mathrm{AlO}_{4}$ and $\mathrm{PO}_{4}$ tetrahedral units arranged in strict alternation, were discovered by d'Yvoire in $1961^{1}$ and first studied systematically by Wilson et al. $^{2-7}$ In recent years, the family of aluminophosphates with an $\mathrm{Al} / \mathrm{P}$ ratio of 1 , traditionally prepared under hydrothermal conditions, has increased with the use of a large variety of organic structure directing agents (SDAs) in solvothermal syntheses. The 1D-chains, 2D-layers and 3D-frameworks that resulted consist of $\mathrm{Al}$ units in different coordination environments $\left(\mathrm{AlO}_{4}, \mathrm{AlO}_{5}\right.$ or $\left.\mathrm{AlO}_{6}\right)$ alternating with $\mathrm{PO}_{4}$ tetrahedral units with one, two or three terminal $\mathrm{P}-\mathrm{O}$ groups, giving rise to a vast range of compositions, including $\mathrm{AlPO}_{4}(\mathrm{OH})^{\text {, }}$, $\mathrm{AlP}_{4} \mathrm{O}_{16}{ }^{9-}, \quad \mathrm{AlP}_{2} \mathrm{O}_{8}{ }^{3-}, \quad \mathrm{Al}_{2} \mathrm{P}_{3} \mathrm{O}_{12}{ }^{3-}, \quad \mathrm{Al}_{3} \mathrm{P}_{4} \mathrm{O}_{16}{ }^{3-}, \quad \mathrm{Al}_{3} \mathrm{P}_{5} \mathrm{O}_{20}{ }^{6-}$, $\mathrm{Al}_{4} \mathrm{P}_{5} \mathrm{O}_{20}{ }^{3-}, \mathrm{Al}_{5} \mathrm{P}_{6} \mathrm{O}_{24}{ }^{3-}, \mathrm{Al}_{6} \mathrm{P}_{7} \mathrm{O}_{27} \mathrm{OH}^{2-} \mathrm{Al}_{11} \mathrm{P}_{12} \mathrm{O}_{48}{ }^{3-}, \mathrm{Al}_{12} \mathrm{P}_{13} \mathrm{O}_{52}{ }^{3-}$ and $\mathrm{Al}_{13} \mathrm{P}_{18} \mathrm{O}_{72}{ }^{15-8,9}$. These AlPO networks provide a wide variety of topologies with different dimensionalities and compositions, resulting in interesting materials, sometimes with unusually large pores. ${ }^{10}$
Organic compounds, particularly amines and quaternary ammonium salts, have been used extensively in the synthesis of nanoporous framework materials. ${ }^{11}$ The organic SDAs direct the crystallization pathway towards a particular framework that would not be formed in its absence. ${ }^{12-15}$ SDAs are encapsulated within the nanoporous frameworks during crystallization, developing strong non-bonding interactions with the framework and thus contributing to the final stability of the system. To be efficient SDAs, organic molecules must be (1) moderately hydrophobic, (2) soluble in the synthesis media without interacting too strongly with the solvent, (3) moderately rigid (to increase selectivity), (4) have high hydrothermal stability to withstand the high temperatures at which syntheses are usually performed, and (5) develop strong non-bonding interactions with the nanoporous framework. ${ }^{16}$

The synthesis of large-pore materials is one of the ultimate targets in zeolite science, especially for the chemical and pharmaceutical industries, because the molecular size of the compounds of interest is often too large to react within the nanopores of the currently available frameworks. In the quest for novel large-pore nanoporous structures, ever larger, bulkier and more complex SDAs have been investigated, and have led to the discovery of a number of new zeolitic topologies. ${ }^{17-25}$ Recently, the first mesoporous chiral zeolite (ITQ-37) was obtained by using a very large, rigid and complex organic SDA. ${ }^{23}$ However, the size and complexity of organic species that can be used as SDAs is restricted by the stability and 
solubility requirements. In practice, molecules with $\mathrm{C} / \mathrm{N}$ ratios below 16 are most common. Therefore, new concepts for the design of efficient organic SDAs are required. ${ }^{26}$

To date, the organic molecules used as SDAs have almost invariably been chosen for the features of single molecular units. In sharp contrast to the very successful use of supramolecular micelle arrangements of surfactants in the synthesis of mesoporous materials, supramolecular chemistry has not been applied in the synthesis of nanoporous materials. This concept in structure-direction has been developed recently by our group $^{27-31}$ and by Corma et $a l^{32}$ The strategy involves the use of molecules that self-assemble as supramolecular aggregates as structure-directing entities. This new concept of structure direction permits relatively simple molecules with suitable size, hydrophobicity and basicity properties, to be used to create framework topologies with larger pores.

The most common driving force for the self-assembly of organic molecules in aqueous solution is the presence of hydrophobic groups in the molecular structure. These groups tend to avoid contact with water, and in turn develop hydrophobic interactions with apolar regions of adjacent molecules, giving rise to supramolecular aggregates. The hydrophobic driving force for aggregation is enhanced if these groups contain aromatic rings that can establish $\pi-\pi$ type interactions. Therefore, 1,3-diphenylguanidine (DPG) (Figure 1) was selected to test this hypothesis in the synthesis of aluminophosphate frameworks; to our knowledge, guanidine-type molecules have only once been used as templates for the synthesis of microporous materials. ${ }^{33}$ The molecule was chosen, because (1) it has distinguishable polar and apolar groups in different molecular regions (a surfactant-like configuration), (2) it can self-aggregate through $\pi-\pi$ type interactions between the aromatic rings, and (3) with four rotatable bonds, it has high conformational flexibility. The synergy between these three features should drive the molecule to form large aggregates in aqueous solution. Aluminophosphate was chosen for the framework composition because of its hydrophilic nature. It was expected that the polar groups in DPG would interact well with hydrophilic AIPO networks. Here we present a multilevel study of the self-assembling structure-directing behavior of DPG during the synthesis of a framework aluminophosphate, which we have designated ICP-1 (for Instituto de Catálisis y Petroleoquímica).

\section{COMPUTATIONAL AND EXPERIMENTAL METHODS}

\section{A) Molecular Mechanics Simulations}

DPG is non-active in UV-Visible fluorescence spectroscopy, and therefore this technique could not be applied to study the aggregation behavior of DPG. ${ }^{28}$ Hence, molecular-mechanicsbased simulations were employed to analyze the aggregation behavior of DPG in aqueous solution in order to understand the molecular features governing the supramolecular chemistry that drives the formation of self-assembled aggregates. Molecular structures of DPG and water molecules were described with the cvff force field. ${ }^{34}$ Protonated DPG $\left(\mathrm{DPGH}^{+}\right)$molecules were studied, as they were found within the ICP-1 structure. The atomic charge distribution of $\mathrm{DPGH}^{+}$ was obtained from DFT calculations, using the B3LYP hybrid functional and the ESP charge calculation method, setting the total net charge to +1 . The positive charge of the $\mathrm{DPGH}^{+}$ cations was compensated by including an equal number of $\mathrm{Cl}^{-}$ anions in the simulations. The atomic charges of water molecules were -0.82 and +0.41 for oxygen and hydrogen, respectively. ${ }^{35}$

Due to the presence of 4 rotatable bonds, and the importance of molecular flexibility when studying struture-direction and supramolecular aggregation issues, ${ }^{16,36}$ a conformational analysis was performed. The conformational space of $\mathrm{DPGH}^{+}$ was scanned by means of the Conformers Calculation Module in Materials Studio, ${ }^{37}$ using a systematic grid scan search method and optimising the molecular structures for each set of dihedral angles.

The aggregation behavior of the $\mathrm{DPGH}^{+}$molecules in water was studied by means of Molecular Dynamics (MD) simulations, using the Discovery code as implemented in Materials Studio. ${ }^{38}$ A $1 \mathrm{DPGH}^{+}: 75 \mathrm{H}_{2} \mathrm{O}$ ratio was used, close to the experimental concentration for the synthesis of ICP-1. 16 $\mathrm{DPGH}^{+}$molecules and $16 \mathrm{Cl}^{-}$anions were included in the simulation cell together with 1200 water molecules. An initial equilibration period of $100 \mathrm{ps}$ of MD simulations in the NPT ensemble at $298 \mathrm{~K}$ was allowed. The density of the systems along this initial MD simulation was averaged, and a frame in the last steps of the MD trajectory with a density close to the averaged value was selected as the starting configuration for the subsequent NVT study. 1000 ps of MD simulations were run, keeping the temperature constant at $373 \mathrm{~K}$ (temperature at which ICP-1 crystallizes). Of this NVT simulation time, only the last 500 ps were used for production. The aggregation behaviour of $\mathrm{DPGH}^{+}$molecules was studied by analysing the Radial Distribution Functions (RDF) of different sets of atoms $\left[\mathrm{g}_{\alpha \beta}(\mathrm{r})\right]$. The concentration profiles were calculated according to: $n_{\alpha(\beta)}(r)={ }_{4 \pi \rho_{\beta} \int_{0}^{r} g_{\alpha \beta}(r)} r^{2} d r$; where $\mathrm{n}_{\alpha(\beta)}(\mathrm{r})$ is the number of $\beta$ species surrounding $\alpha$ at less than a given distance $(r), \rho_{\beta}$ is the bulk number density of atom $\beta$ and $g_{\alpha \beta}(r)$ is the $\alpha-\beta$ RDF.

\section{B) Synthesis and General Characterisation Details}

The aluminophosphate ICP-1 was synthesized hydrothermally using 1,3-diphenylguanidine (DPG, Sigma-Aldrich, 97\%) as the SDA at temperatures ranging between 100 and $180{ }^{\circ} \mathrm{C}$. Pseudoboehmite (Pural SB-1 77.5\% $\mathrm{Al}_{2} \mathrm{O}_{3}$, Sasol) and phosphoric acid (Sigma-Aldrich, 85\%), were used as sources of $\mathrm{Al}$ and $\mathrm{P}$, respectively. A series of different molar compositions (see Table S1 in the Supporting Information) were investigated. After the reagents were mixed, the gels were heated statically at the required temperature $\left(100-180{ }^{\circ} \mathrm{C}\right)$ under autogeneous pressure for a specific period of time (from 3 to 96 hours). The resulting solids were collected by filtration, washed thoroughly with water and ethanol and dried at room temperature. ICP-1 samples were further purified by subjecting them to an ultrasonic treatment followed by decantation.

ICP-1 was characterized by different physicochemical techniques. X-ray powder diffraction (XPD) patterns were measured on a Philips X'PERT diffractometer (reflection geometry) using Ni-filtered $\mathrm{CuK} \alpha$ radiation. The crystal morphology was studied by scanning electron microscopy (SEM) using a Hitachi TM-1000 Tabletop microscope. The organic content of the samples was analyzed by thermogravimetric analysis (TGA) using a Perkin-Elmer TGA7 instrument. Elemental analyses for $\mathrm{Al}$ and $\mathrm{P}$ were performed by inductively coupled plasma optical emission spectrometry (ICP-OES, PerkinElmer 3300DV instrument) after sample dissolution by alkaline fusion. MAS NMR spectra were recorded at room temperature using a Bruker AV- 400-WB spectrometer with a 4 $\mathrm{mm}$ probe spinning at $10 \mathrm{kHz} .{ }^{1} \mathrm{H}$ to ${ }^{13} \mathrm{C}$ cross polarization 
(CP) spectra were recorded using $\pi / 2$ rad pulses of $3 \mu$ s for ${ }^{1} H$, a contact time of $3.5 \mathrm{~ms}$ and a recycle delay of $4 \mathrm{~s}$.

\section{C) Single Crystal Structure Solution and Rietveld refine- ment}

Microscopic examination of the sample revealed thin platelike crystals with matt surfaces. One of these was selected for single-crystal X-ray diffraction data collection on an $\mathrm{X}$ 'Calibur Onyx diffractometer, using MoK $\alpha$ radiation (Table $\mathrm{S} 2$ in the Supporting Information). Optimization of the measurement and subsequent data reduction were carried out using the CrysAlysPro software, version 1.171.34.49. ${ }^{39}$ Structure analysis was performed in the WinGX suite of programs. ${ }^{40}$ The crystal structure was determined using the direct methods program in Shelxs-97, and refined using Shelxl-97. ${ }^{41}$ Highresolution powder diffraction data were collected on a ground sample sealed in a rotating $0.3 \mathrm{~mm}$ glass capillary on the powder diffractometer at the Swiss-Norwegian Beamlines (SNBL) at the European Synchrotron Radiation Facility (ESRF) in Grenoble, France (Table S3 in the Supporting Information). The Rietveld refinement was performed using the program package XRS $-82,{ }^{42}$ and the structure drawings were produced using the program CrystalMaker. ${ }^{43}$ The plots with observed, calculated and differences patterns were prepared with the programme ppp $14^{44}$

\section{D) Quantum Mechanics Simulations}

Due to the difficulty in localizing $\mathrm{H}$ atoms in diffraction studies, the location of the protons was determined by Density Functional Theory calculations, employing the PBE generalized gradient approximation as functional ${ }^{45}$ and a numerical basis set, using the DMol3 code, ${ }^{46}$ as implemented in Materials Studio. ${ }^{47}$ Dispersion interactions were accounted for through the Grimme dispersion method $(\mathrm{DFT}+\mathrm{D}) .{ }^{48}$ Starting from the experimentally solved structure, $3 \mathrm{H}$ atoms per unit cell were manually inserted in selected positions, and geometry optimization procedures were applied to determine the most stable location.

On the other hand, in order to understand the ${ }^{13} \mathrm{C}$ NMR spectra of the ICP-1 material observed experimentally, the theoretical ${ }^{13} \mathrm{C}$ NMR spectrum was calculated by using DFT $+\mathrm{D}$. This time, plane-waves were used for the basis set (with a cutoff of $500 \mathrm{eV}$ ), and the PBE as functional, using the gauge-including projector augmented-wave method (GIPAW), as implemented in the CASTEP ${ }^{49}$ module in Materials Studio. ${ }^{50}$ This computational methodology has been shown to predict NMR properties of zeolite materials accurately. ${ }^{51}$ The geometry of the ICP1 structure, including protons, was first optimized at this level of theory, and then the NMR properties were calculated to obtain the absolute shieldings of the nuclei. The chemical shift for a nucleus at a given position $(\delta(\mathrm{r}))$ is defined as $\delta(\mathrm{r})=\sigma_{\text {ref }}$ $-\sigma(\mathrm{r})$, where $\sigma(\mathrm{r})$ is the isotropic shielding obtained in the calculations. To facilitate comparison with the experimental chemical shifts, $\sigma_{\text {ref }}$ was selected to coincide with experimental values.

\section{RESULTS}

\section{A) Computational analysis of $\mathrm{DPGH}^{+}$aggregation behavior}

$\mathrm{DPGH}^{+}$possesses four rotatable bonds. Analysis of the 1296 different conformers generated revealed that only 3 of them are non-equivalent and stable, with small energy differences

between them (Figure 1). In conformation A, the two aromatic rings are close to each other, developing intramolecular $\pi-\pi$ type interactions. Two well-defined areas can be recognized: a hydrophobic one, containing the aromatic rings, and a hydrophilic one, with the guanidinium group, giving rise to a surfactant-like configuration but on a smaller scale. In the two other conformations ( $\mathrm{B}$ and $\mathrm{C}$ ), the aromatic rings are located on opposite sides of the molecule, without developing intramolecular interactions. Relevant distances that will be used to distinguish between the different conformers during the MD simulations are shown in yellow.

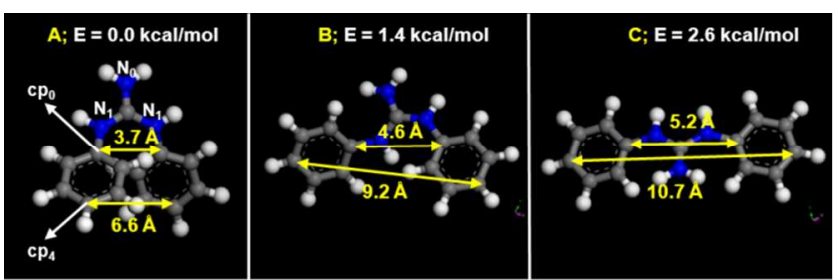

Figure 1. Three stable non-equivalent conformers (A, B and C) and the corresponding relative energies (in $\mathrm{kcal} / \mathrm{mol}$ ) and distinguishing interatomic distances (in yellow); conformer A includes the nomenclature of the atom-types for the RDF

(a)

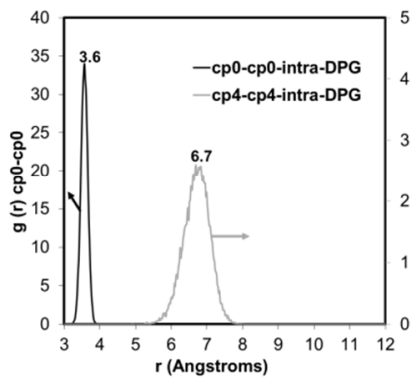

(c)

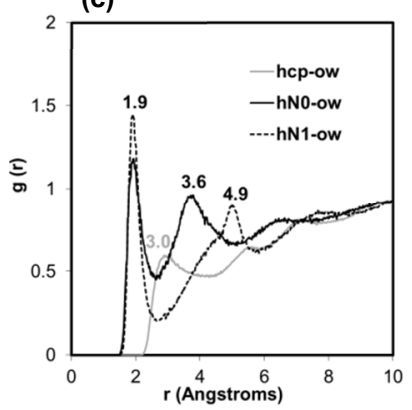

calculations.

Figure 2. Radial Distribution Functions (g(r)) and concentration profiles of different sets of atoms. (a) Intramolecular RDF between $\mathrm{cp}_{0}$ atoms (aromatic $\mathrm{C}$ with $\mathrm{N}$ attached, in black) and between $\mathrm{cp}_{4}$ atoms (aromatic $\mathrm{C}$ in para-position, in grey). (b) Inter-molecular (black) and intra-molecular (grey) RDFs between all aromatic $\mathrm{C}$ atoms (cp). (c) Intermolecular RDF between $\mathrm{O}$ atoms of water molecules (ow) and $\mathrm{H}$ atoms attached to aromatic $\mathrm{C}$ atoms (hcp, grey line), to $\mathrm{N}_{0}$ atoms (hN0, solid black line) and to $\mathrm{N}_{1}$ atoms (hN1, dashed black line) (see Figure 1 for nomenclature). (d) Associated intermolecular concentration profiles.

Next, $\mathrm{DPGH}^{+}$conformations in water were studied by examining the Radial Distribution Function of different sets of atoms during the MD simulations (Figure 2). Two intramolecular interatomic distances between non-bonded aromatic $\mathrm{C}$ 
atoms can be used to distinguish between the three conformations (Figure 1, yellow). Analysis of the intramolecular $\mathrm{RDF}$ between $\mathrm{cp}_{0}$ atoms (the aromatic $\mathrm{C}$ atoms with the guanidinium group attached) and between $\mathrm{cp}_{4}$ atoms (the aromatic $\mathrm{C}$ atoms in para position to the guanidinium groups) showed single peaks at 3.6 and $6.7 \AA$, respectively (Figure $2 \mathrm{a}$, black and grey lines). Both distances are very similar to those in conformer A (Figure 1), thus evidencing that $\mathrm{DPGH}^{+}$mostly adopt this type of conformation in water. Such preferential conformation is due to the hydrophobic nature of these rings which makes them to avoid exposure to water, forcing the molecules to adopt a conformation where the contact of this hydrophobic region with water is minimized, while maximizing the contact of the hydrophilic region (guanidinium), in a configuration resembling that of surfactant molecules in micelles.

The aggregation behavior of $\mathrm{DPGH}^{+}$molecules in water solution was studied by analyzing the intermolecular RDF between aromatic rings of different molecules (Figure 2b). An intense peak is observed between 4 and $6 \AA$ in the intermolecular RDFs between all aromatic $\mathrm{C}$ atoms (Figure 2b, black line), indicating a preferential location of aromatic rings at such distance, which corresponds to the usual $\pi-\pi$ type interactions, evidencing a very intense aggregation. The peaks observed in the intramolecular RDFs between aromatic $\mathrm{C}$ atoms (Figure 2b, grey line) indicate a close intramolecular interaction between the two aromatic rings of a single molecule, providing further evidence that the molecules in such aggregates have a preference for conformation $\mathrm{A}$.

The interaction between the different $\mathrm{H}$ atoms of $\mathrm{DPGH}^{+}$ with $\mathrm{O}$ atoms of water (Figure $2 \mathrm{c}$ and $\mathrm{d}$ ) was analyzed next. A very strong interaction between the polarized $\mathrm{H}$ atoms attached to the $\mathrm{N}$ atoms of the guanidinium group, both $\mathrm{N}_{0}$ and $\mathrm{N}_{1}$ (see Figure 1 for nomenclature), and the $\mathrm{O}$ atoms of the water molecules is observed at $1.9 \AA$ (Figure $2 \mathrm{c}$, solid and dashed black lines), which indicates that strong H-bonds are established. A second peak appears at 3.6 and $4.9 \AA$ for the $\mathrm{H}$ $\mathrm{N}_{0}$ and $\mathrm{H}-\mathrm{N}_{1}$ atoms, respectively, suggesting the presence of a second shell of water molecules surrounding these $\mathrm{H}-\mathrm{N}$ groups, but closer in the case of $\mathrm{N}_{0}$. These results show a more concentrated $\mathrm{H}$-bonding network around the $\mathrm{N}_{0}$ atoms, possibly because they are more accessible - they occupy the most external area of conformer $\mathrm{A}-$ and because they carry the positive charge. This is also evident in the concentration profiles (Figure $2 \mathrm{~d}$ ), which show a higher number of water molecules (for $\mathrm{HN}_{0}$ ) at distances beyond $2.4 \AA$. In contrast, a much weaker interaction is observed between water and the $\mathrm{H}$ atoms of the aromatic rings (Figure 2c, grey line), where the first peak, of very low intensity, occurs at $3.0 \AA$. In other words, fewer water molecules surround the hydrophobic region of the

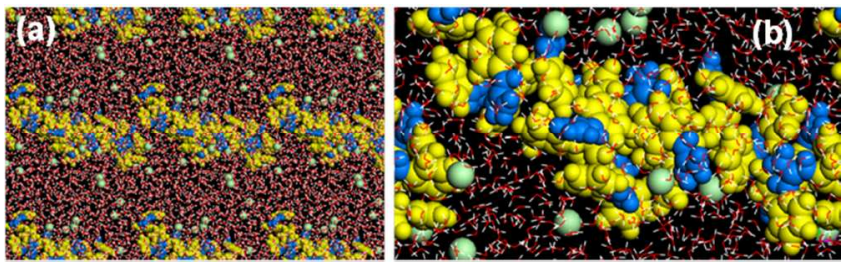

molecular rings (Figure 2d, grey line).

Figure 3. (a): Snapshot (time $=1000.0 \mathrm{ps}$ ) of the molecular arrangement of $\mathrm{DPGH}+$ in water: $\mathrm{DPGH}^{+}(\mathrm{CPK}$ model, with hydrophobic (aromatic) and hydrophilic (guanidinium) regions in yellow and blue, respectively), $\mathrm{Cl}^{-}$(CPK model, green), $\mathrm{O}$ (water) (line model, red) and $\mathrm{H}$ (water) (line model, white). (b): Detail.

A detail of the molecular arrangement of $\mathrm{DPGH}^{+}$as large aggregates in water solution is shown in Figure 3 (at the end of the MD simulation, time $=1000.0 \mathrm{ps}$ ). Very large supramolecular aggregates with the hydrophobic (yellow) regions towards the center of the aggregates, and the hydrophilic (blue) regions towards the outer region in contact with the water molecules, are formed (Figure $3 \mathrm{a}$ and detail in $\mathrm{b}$ ). This results in two well-defined regions in the simulation box, a region rich in organic aggregates and a region rich in water molecules, which will eventually be replaced by hydrophilic AlPO species in an aluminophosphate synthesis.

\section{B) Synthesis of ICP-1}

The use of DPG under different gel compositions and hydrothermal conditions has enabled the crystallization of a novel crystalline aluminophosphate, ICP-1 (see Table S1 in the Supporting Information). The initial physico-chemical characterization of this material (XPD, TGA, SEM) is displayed in Figure 4. ICP-1 crystallizes from synthesis gels with molar compositions: $1.5-2 \mathrm{DPG}: 1 \mathrm{Al}_{2} \mathrm{O}_{3}: 1 \mathrm{P}_{2} \mathrm{O}_{5}: 110 \mathrm{H}_{2} \mathrm{O}$, that is, those with high organic content that provide mildly acidic $\mathrm{pHs}$ (4.5-5), and under a wide range of temperatures $\left(100-180^{\circ} \mathrm{C}\right.$, although only at short times at 150 and $180^{\circ} \mathrm{C}$ ). High temperatures and long crystallization times provoke the degradation of DPG producing $\mathrm{NH}_{4}^{+}$fragments that results in the formation of an ammonium aluminophosphate, AlPO-15 (Figure S1 in the Supporting Information). ${ }^{52}$ Temperature-programmed XRD experiments show that ICP- 1 is stable up to $250^{\circ} \mathrm{C}$, but after this DPG is released and the structure collapses (Figure S2 in the Supporting Information). SEM images of ICP-1 (Figure 4c) show that the crystallites form large rectangular plates with approximate crystal sizes around $300 \times 100 \times 50$ $\mu \mathrm{m}^{3}$.
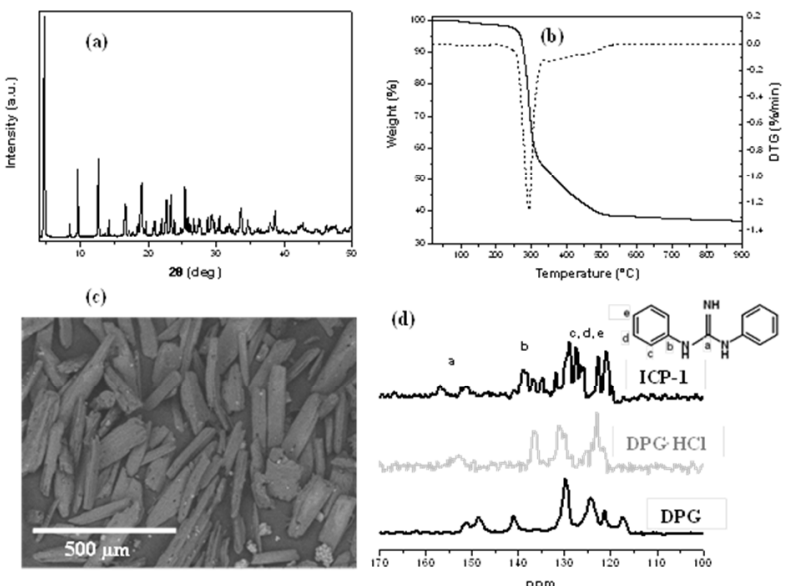

Figure 4. Characterization of ICP-1 (prepared under conditions: A-1.5-110-100 for 4 days, Table S1 in the Supporting Information). (a) XRD pattern, (b) Thermogravimetric analyses, (c) Scanning Electron Micrograph of ICP-1; (d) ${ }^{13} \mathrm{C} \mathrm{CP}$ MAS-NMR of ICP-1 (top), protonated DPG hydrochloride (DPG·HCl, middle) and neutral DPG (bottom).

The incorporation of organic molecules was studied by thermogravimetric analysis and ${ }^{13} \mathrm{CP}$ MAS NMR. TGA (Figure $4 \mathrm{~b}$ ) shows a very large weight loss, suggesting that ICP-1 is a low-dimensional material, because $3 \mathrm{D}$ nanoporous 
frameworks usually have a much lower organic content. The main weight loss, between 180 and $325^{\circ} \mathrm{C}$, is due to the release of DPG molecules. A subsequent weight loss, at temperatures higher than $325^{\circ} \mathrm{C}$, is associated with a further removal of organic residues that were occluded after the structure collapse. The chemical integrity of DPG within the network was verified by ${ }^{13} \mathrm{C}$ CP MAS-NMR (Figure 4d). For comparison, the NMR spectra of isolated neutral DPG and protonated $\mathrm{DPGH}^{+}$Chloride (after addition of equimolar amounts of $\mathrm{HCl}$ and recrystallization from ethanol) are also displayed. ${ }^{13} \mathrm{C} \mathrm{CP}$ MAS-NMR shows unambiguously that DPG is incorporated intact within the structure (see assignments of the different bands in Figure $4 d$ ). The ${ }^{13} \mathrm{C}$ CP MAS NMR spectrum of ICP1 shows more similarities with that of protonated DPG than that of neutral DPG, suggesting that DPG is incorporated as charged species. It is worth noting that the guanidinium $\mathrm{C}$ atom displays two distinct signals at $151 \mathrm{ppm}$ and $157 \mathrm{ppm}$, suggesting two different environments. The $\mathrm{Al} / \mathrm{P}$ ratio (obtained by ICP elemental analyses) is 0.5 .

\section{C) Single Crystal Structure Solution of ICP-1 and Rietveld refinement}

Single-crystal X-ray diffraction data revealed a triclinic unit cell $(\mathrm{a}=7.6656(2) ; \mathrm{b}=10.7143(2) ; \mathrm{c}=18.5600(5) ; \alpha=$ $88.855(2) ; \beta=88.210(2) ; \gamma=74.223(2) ; \mathrm{V}=1466.12(5))$. However, the intensity statistics were not reliable enough to determine whether or not the structure was centrosymmetric. Therefore, an attempt to solve the structure in the space group $P 1$ was made first. This revealed chains of $\mathrm{Al}-\mathrm{O}$ tetrahedra connected to $\mathrm{P}-\mathrm{O}$ tetrahedra and four diphenylguanidine (DPG) molecules in the interchain space. Several missing atoms were readily located in the difference Fourier map. This model was refined, but resulted in relatively high $R$-values and a high residual electron density (Table S4 in the Supporting Information). A subsequent check of the geometry with the program PLATON ${ }^{53}$ suggested that the structure was likely to be centrosymmetric. Therefore, the structure was re-solved and refined using the symmetry $P_{1}^{\overline{1}}$. The asymmetric unit featured $\mathrm{AlP}_{2} \mathrm{O}_{8}$ chains along the $a$ axis, and two DPG species in different conformations in the interchain space. Residual electron density near $\mathrm{N} 1$ and $\mathrm{N} 4$ that could correspond to $\mathrm{H}$ atoms involved in $\mathrm{N}^{\cdots} \mathrm{H}^{\cdots} \mathrm{O}$ bonds between DPG and the aluminophosphate chain was observed. Nonetheless, these $\mathrm{H}^{\prime} \mathrm{s}$ were added at calculated positions. Electron density corresponding to an $\mathrm{H}$ atom bonded to $\mathrm{O} 8(\mathrm{P}-\mathrm{OH})$ appeared afterwards. The rest of the $\mathrm{H}$ atoms of the DPG species were also added at calculated positions, although those in the aromatic rings could be observed in the difference map. The arrangement of the organic species resulted in an interchain space occupied by aromatic rings stacked along the $a$ axis. Although this model did produce improved $R$-values and reasonable chemistry, it could not be refined to the quality required for single-crystal analysis (Table S5 in the Supporting Information). These results are the consequence of the quality of the measured data ( $R$ (int), $R$ (sigma) in Table S5). The $R$ (int) value reflects the precision of the measurement, that is, how well the redundant reflection sets agree. Such a high value can be a consequence of many factors, but in this case it was assumed to arise from the fact that the single crystal was in fact an aggregate of several very thin plate-like crystals stacked on top of one another. As it was not possible to re-measure the sample with absolute certainty that the crystal would be single, the model obtained from the single crystal diffraction data $(P$ $\overline{1}$ ) was refined using X-ray powder diffraction data.
Initially, the background was estimated and then re-adjusted manually during the course of the refinement. Profile parameters (zero correction, unit cell, peak widths) and structural parameters (atomic coordinates, scale) were refined. The atomic positions obtained from the single crystal structure solution were used as the initial model structure. No attempt was made to refine atomic displacement parameters. The values were simply set to the expected values ( 1 for $\mathrm{Al}$ and $\mathrm{P}$, 2 for $\mathrm{O}$ and 3 for $\mathrm{C}, \mathrm{N}, \mathrm{H})$. Geometric restraints were imposed on the bond distances and angles of all atoms for the first cycles of refinement, and their weight relative to the diffraction pattern was decreased progressively until they could be removed completely in the last cycles. Hydrogen atoms were added to the organic species in the calculated positions (using the program Mercury ${ }^{54}$ ) in the final model. Two $\mathrm{H}$ atoms were added to N1 and N4 in accordance with the ${ }^{13} \mathrm{C}$ MAS-NMR, which suggested that DPG was protonated, and with the earlier single-crystal results and their distances to $\mathrm{O}$ atoms of the aluminophosphate chain. An $\mathrm{H}$ atom was added to form a $\mathrm{P}-\mathrm{OH}$ group ( $\mathrm{P} 2-\mathrm{O} 8-\mathrm{H} 29)$ according to single crystal results and $\mathrm{P}-\mathrm{O}$ distances, as discussed later.

In order to examine the possibility of disorder in DPG moieties, the occupancies of all atom positions were refined. They converged to values close to one, suggesting that the DPG molecules are indeed fully ordered and play a structural role in the ICP-1 material, rather than just being space fillers in the interchain region. The difference Fourier map of this model proved to be featureless. No other species could be found on the chains or in the interchain space. This confirmed that the model was complete. The $R$-values of this final model were $R_{F}$ $=0.109$ and $R_{w p}=0.334\left(R_{\text {exp }}=0.288\right)$. The crystallographic data are given in Table S6 and the fit of the profile calculated for this model to the experimental data is shown in Figure S3 in the Supporting Information. Selected interatomic distances and bond angles for the AlPO chain and the organic molecules are given in Table 1 and Table S7; Table S8 contains the

\begin{tabular}{c|c|c|c|c|c}
\hline \multicolumn{7}{c}{ Distances $(\boldsymbol{A})$} \\
\hline Al1-O5 & 1.75 & $\mathrm{P} 1-\mathrm{O} 2$ & 1.52 & $\mathrm{P} 2-\mathrm{O} 7$ & 1.52 \\
\hline Al1-O4 & 1.74 & $\mathrm{P} 1-\mathrm{O} 3$ & 1.51 & $\mathrm{P} 2-\mathrm{O} 8$ & 1.55 \\
\hline Al1-O1 & 1.74 & $\mathrm{P} 1-\mathrm{O} 1$ & 1.53 & $\mathrm{P} 2-\mathrm{O} 6$ & 1.51 \\
\hline A11-O6 & 1.73 & $\mathrm{P} 1-\mathrm{O} 4$ & 1.52 & $\mathrm{P} 2-\mathrm{O} 5$ & 1.54 \\
\hline \multicolumn{7}{|c}{ Angles $\left({ }^{\circ}\right)$} \\
\hline O-T-O & \multicolumn{7}{|c|}{$\mathrm{P} 1-\mathrm{O} 1-\mathrm{A} 11$} & 136.9 & \\
\hline min & 108.1 & & $\mathrm{P} 1-\mathrm{O} 4-\mathrm{A} 11$ & 130.9 & \\
\hline max & 110.8 & & $\mathrm{P} 2-\mathrm{O} 5-\mathrm{A} 11$ & 139.8 & \\
\hline avg & 109.5 & & $\mathrm{P} 2-\mathrm{O} 6-\mathrm{A} 11$ & 148.6 & \\
\hline
\end{tabular}

atomic coordinates of ICP-1.

Table 1. Selected interatomic distances $(\AA)$ and angles $\left(^{\circ}\right)$ for the inorganic AlPO chains of ICP-1.

The refined structure is consistent with that obtained from the single crystal analysis. The asymmetric unit is composed of $\left[\mathrm{AlP}_{2} \mathrm{O}_{8}\right]^{3-}$ units and two DPG cations with different conformations. Since all the atoms occupy general positions, the unit cell composition is $\left|\left(\mathrm{C}_{13} \mathrm{~N}_{3} \mathrm{H}_{14}\right)_{4}\right|\left[\mathrm{Al}_{2} \mathrm{P}_{4} \mathrm{O}_{16} \mathrm{H}_{2}\right]$.

The ICP-1 structure consists of independent AlPO chains running parallel to the $a$ axis, and connected through a complex H-bond network with the polar moieties of the organic DPG cations (Figure 5). Both P1 and P2 atoms are bonded to two bridging $(\mathrm{P}-\mathrm{O}-\mathrm{Al}$ linkages) and two terminal oxygens, whereas the $\mathrm{Al}$ atom is fully 4-connected via four $\mathrm{Al}-\mathrm{O}-\mathrm{P}$ linkages. This results in two different 4-rings: one with $2 \mathrm{Al}$ 
atoms and $2 \mathrm{P} 1$ atoms and the second with $2 \mathrm{Al}$ and $2 \mathrm{P} 2$ atoms. The rings are connected through the $\mathrm{Al}$ atom to form the chain (Figure 6a and b). The geometry of the AlPO chain is reasonable, with refined $\mathrm{Al}-\mathrm{O}$ and $\mathrm{P}-\mathrm{O}$ distances (Table 1) within the normal range for these bonds, around 1.74 and 1.52 $\AA$, respectively. The tetrahedral $\mathrm{O}-\mathrm{T}-\mathrm{O}$ angles are close to $109.5^{\circ}$, and $\mathrm{T}-\mathrm{O}-\mathrm{T}$ bond angles range from 130.9 to $148.6^{\circ}$, the former being small for a zeolite but normal for $\mathrm{Al}-\mathrm{O}-\mathrm{P}$. The P2-O8 distance is particularly long (1.55 $\AA$ ), suggesting that the $\mathrm{O} 8$ atom might be protonated, forming a terminal $\mathrm{P}-\mathrm{OH}$ group. This is supported by the single-crystal analysis, where residual electron density appeared at a position suitable for an $\mathrm{H}$ atom bonded to $\mathrm{O} 8$. This $\mathrm{H}$ was included in the final model.
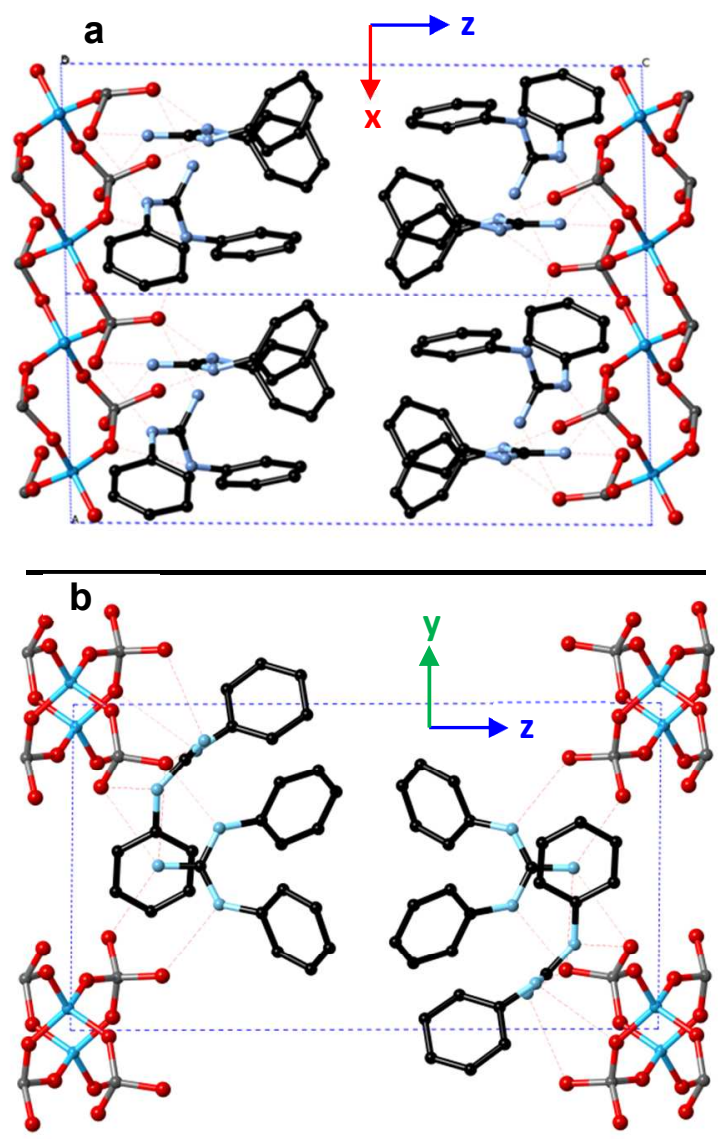

Figure 5. Two views of the ICP-1 structure show the AlPO chains along the $a$ axis and the DPG species between them (some symmetry-equivalent DPG molecules have been omitted for clarity in b).

The free distance between the inorganic aluminophosphate chains (assuming a $1.35 \AA$ ionic radius for oxygen) is $2.12 \AA$ along the $b$ axis, and $10.68 \AA$ along the $c$ axis. This space is filled with the organic species, where the guanidinium polar moiety is oriented towards the AlPO chains, and the aromatic rings towards the inter-chain space. In the hydrophobic region, the aromatic rings of neighboring DPG moieties are separated by $4.0 \AA$. The molecular structure of DPG-1 (N1, N2 and N3 in Figure $6 \mathrm{c}$ ) has its benzyl rings close to each other, with $\mathrm{cp}_{0^{-}}$ $\mathrm{cp}_{0}$ and $\mathrm{cp}_{4}-\mathrm{cp}_{4}$ distances of 3.2 and $6.1 \AA$, and an angle of 70 $\circ$ between the planes containing the rings, which closely corresponds to conformation A described in Section A (the preferred conformation in water). In DPG-2 (N4, N5, N6 in Fig- ure $6 \mathrm{c}$ ), the benzyl rings are further apart, with $\mathrm{cp}_{0}-\mathrm{cp}_{0}$ and $\mathrm{cp}_{4}-\mathrm{cp}_{4}$ distances of 4.3 and $9.2 \AA$, and an angle of $130^{\circ}$ (this corresponds to conformation B in Section A). Selected bond distances and angles of the organic molecules are summarized in Table S7 in the Supporting Information.
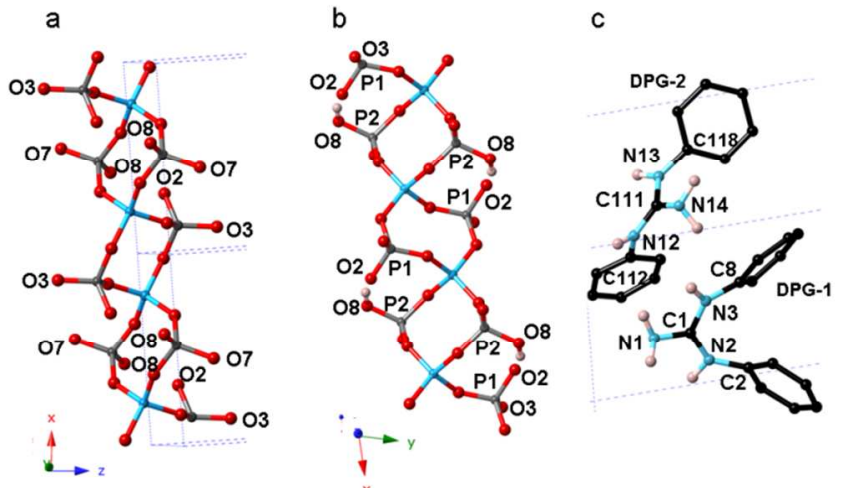

Figure 6. The ICP-1 structure. (a) The AlPO chain featuring the terminal $\mathrm{O}$ atoms bonded to the two different $\mathrm{P}$ atoms, and (b) the pseudo-4-ring formed by $\mathrm{Al}, \mathrm{P} 1, \mathrm{P} 2$ and the $\mathrm{H}$-bond to the two terminal $\mathrm{O}$ atoms. (c) The two non-equivalent diphenylguanidine species DPG-1 $(\mathrm{C} 8, \mathrm{~N} 3, \mathrm{~N} 2, \mathrm{C} 2, \mathrm{C} 1, \mathrm{~N} 1)$ and DPG-2 (C21, N6, N4, C14, N5, C15).
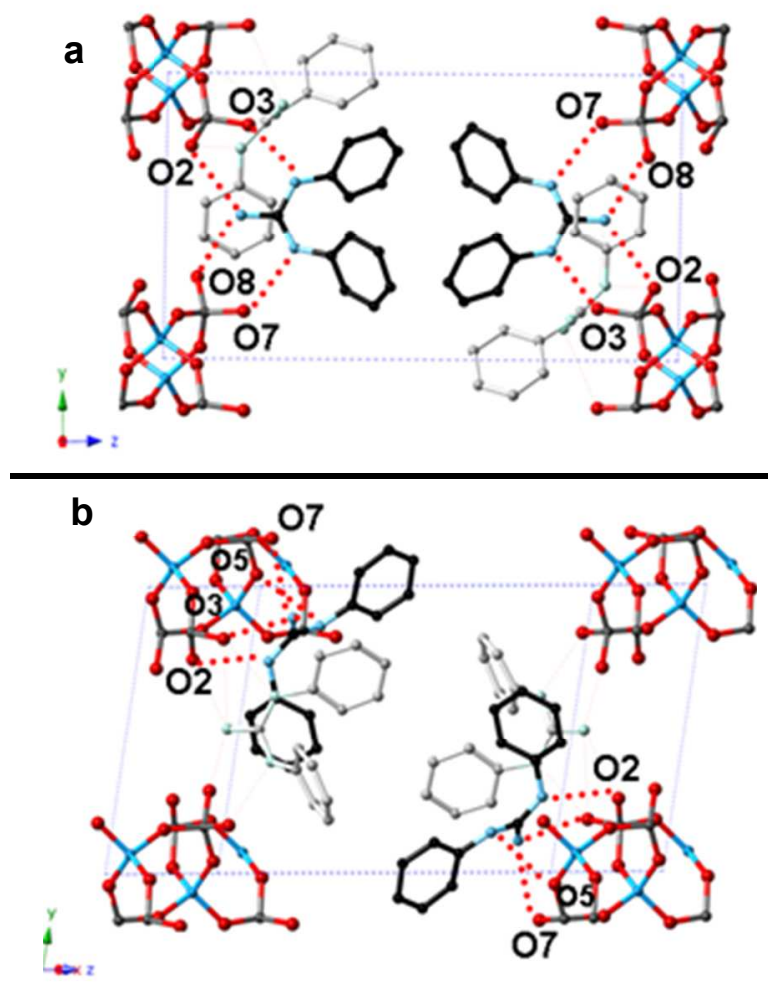

Figure 7. (a) Structure of ICP-1 viewed down the a axis. DPG-1 (black) makes two H-bonds with the $\mathrm{O}$ atoms of the AlPO chain. DPG-2 is shown in grey. (b) Structure of ICP-1 viewed down the diagonal between $b$ and $c$ axes: DPG-2 (black) makes H-bonds with the $\mathrm{O}$ atoms of the AlPO chain. DPG-1 is shown in grey. Some symmetrically equivalent molecules have been deleted for clarity.

The three $\mathrm{N}$ atoms in each of the two non-equivalent organic species are within $\mathrm{H}$-bonding distance of $\mathrm{O}$ atoms in the aluminophosphate chain (Figure 7 and Table S7). Each of the 
guanidinium $\mathrm{N}_{0}$ atoms ( $\mathrm{N} 1$ or $\mathrm{N} 4$ ) makes two H-bonds to terminal $\mathrm{O}$ atoms, and each of the two $\mathrm{N}_{1}$ nitrogens makes an $\mathrm{H}$-bond to another $\mathrm{O}$ atom. All the H-bonds of DPG-2 are intra-chain, whereas those of DPG-1 establish inter-chain linkages along the $b$ axis. It is not possible to determine from the diffraction data whether the $\mathrm{H}$ atoms involved in the $\mathrm{N}^{\cdots} \mathrm{H}^{\cdots} \mathrm{O}$ bonds are bonded to the $\mathrm{O}$ or to the $\mathrm{N}(\mathrm{N} 1, \mathrm{~N} 4)$ atom.

\section{D) DFT+D: Localization of protons}

In the previous section it has been shown that the asymmetric unit of ICP-1 is composed of $\mathrm{AlP}_{2} \mathrm{O}_{8}{ }^{3-}$ units with three negative charges that need to be balanced. There are two DPG molecules with $-\mathrm{C}=\mathrm{NH}$ groups that can be protonated, and four terminal $\mathrm{O}(\mathrm{P})$ atoms $(\mathrm{O} 8, \mathrm{O} 7, \mathrm{O} 3$ and $\mathrm{O} 2)$ in the inorganic network that can bear a proton (Figure 8). Because protons are difficult to locate using X-ray diffraction techniques, the different $\mathrm{H}$ location possibilities were studied by $\mathrm{DFT}+\mathrm{D}$ geometry optimization. Calculations showed that when the three protons were attached to three $\mathrm{O}$ atoms of the inorganic network (O8, O7 and O3), two of them (attached to $\mathrm{O} 7$ and O3) passed to the $\mathrm{N}_{0}$ atom of the DPG molecules, clearly confirming the higher stability of the protons attached to organic molecules. Therefore, it becomes clear that the DPG molecules of ICP-1 will be protonated.

Table 2. H-location and relative energies (in $\mathrm{kcal} / \mathrm{mol}$ per $\mathrm{AlP}_{2} \mathrm{O}_{8} \mathrm{H}_{3}: 2 \mathrm{DPG}$ unit) calculated by $\mathrm{DFT}+\mathrm{D}$ methodologies (DMol3 and CASTEP).

\begin{tabular}{c|c|c|c|c}
\hline \multirow{2}{*}{ System } & \multicolumn{3}{|c|}{ H location } & \multirow{2}{*}{$\begin{array}{c}\text { Relative E } \\
\text { DMol3/CASTEP }\end{array}$} \\
\cline { 2 - 4 } & 1 & 2 & 3 & $0.0 / 0.0$ \\
\hline 1 & DPG-1 & DPG-2 & O8 & O7 \\
\hline 2 & DPG-1 & DPG-2 & O7.1/17.3 \\
\hline 3 & DPG-1 & DPG-2 & O3 & $33.4 / 32.5$ \\
\hline 4 & DPG-1 & DPG-2 & O2 & Not min* \\
\hline 5 & DPG-1 & O8 & O7 & Not min* \\
\hline 6 & DPG-2 & O8 & O7 & Not min* \\
\hline 7 & DPG-1 & O8 & O2 & $43.0 /---$ \\
\hline 8 & DPG-2 & O8 & O2 & $40.7 /---$ \\
\hline 9 & DPG-1 & O8 & O3 & $38.2 /---$ \\
\hline 10 & DPG-2 & O8 & O3 & $41.5 /---$ \\
\hline 11 & DPG-2 & O7 & O2 & $47.7 /---$ \\
\hline 12 & DPG-1 & DPG-1 & DPG-2 & Not min* \\
\hline
\end{tabular}

*indicates that the system was not a minimum on the Potential Energy Surface, and the proton moved to a neutral DPG molecule (entries 5 and 6) or to $\mathrm{O} 8$ (entries 4 and 12).

Many different combinations were studied (energy results are reported on Table 2), i) having the two molecules protonated and the third proton on a terminal $\mathrm{O}$ atom of the inorganic network (O8, O7, $\mathrm{O} 3$ or $\mathrm{O} 2$, entries $1-4)$, ii) having only one molecule protonated and two protons on the inorganic chain (entries 5-11), and iii) having all the protons on the DPG molecules (entry 12). When two protons were attached to the chain and only one to a DPG molecule (entries 5-11), the systems were much less stable: in many cases, they were not even minima on the potential energy surface (PES) and geometry optimization moved the protons to the neutral DPG molecules. The systems that were indeed minima had very high energies (higher than $40 \mathrm{kcal} / \mathrm{mol}$ per u.c.). The system with all the protons on DPG (entry 12) was not a minimum on the PES and one of the protons was moved to the chain. Instead, the most stable situations were found for the systems with the two molecules protonated and only one proton attached to the inorganic network (entries 1-4). A much more stable situation was found when the proton was attached to O8. The system with the two DPG molecules protonated and the third proton attached to $\mathrm{O} 8$ is clearly the preferred one.
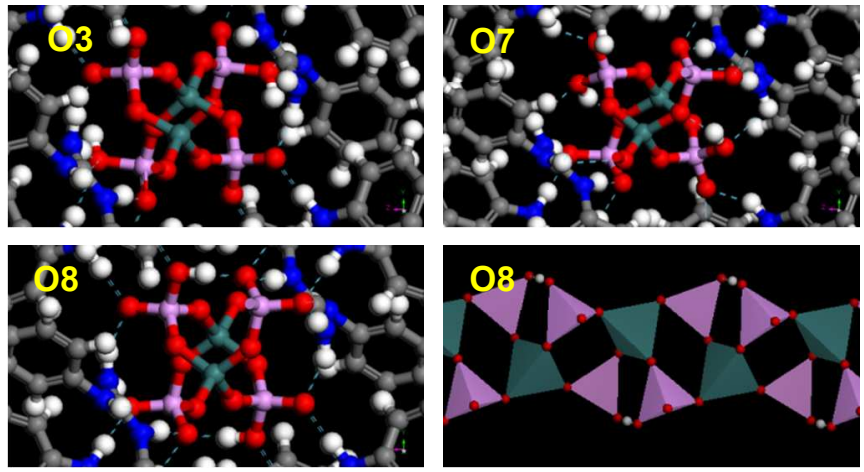

Figure 8. Calculated geometry of ICP-1 with the two DPG molecules protonated and the third proton on the different terminal $\mathrm{O}$ positions (top-left and right and bottom-left) and a polyhedral view of the structure of the $\mathrm{AlP}_{2} \mathrm{O}_{8} \mathrm{H}$ chains (bottom-right).

Figure 8 shows the final location of the protons in the different cases. A proton sited on $\mathrm{O} 3$ is the less stable because it cannot form an $\mathrm{H}$-bond to another terminal $\mathrm{O}$ atom of the $\mathrm{AlP}_{2} \mathrm{O}_{8}$ chain. If $\mathrm{O} 7$ bears the proton, the situation is more stable, because an intra-chain $\mathrm{H}$-bond can form with a bridging $\mathrm{O}(\mathrm{H} \cdots \mathrm{O}$ distance of $1.82 \AA)$ to form a pseudo 3 -ring. However, the most stable location for the proton is near O8, where it can form a very strong $\mathrm{H}$-bond with a terminal $\mathrm{O}(\mathrm{O} 2$, $\mathrm{H} \cdots \mathrm{O}$ distance of $1.52 \AA$ ), and create a pseudo-4-ring that stabilizes the $\mathrm{AlP}_{2} \mathrm{O}_{8}$ chain (Figure 8 bottom-right) and increases its rigidity. This chain is particularly stable due to the presence of alternating 4-rings $\left(2 \mathrm{AlO}_{4}\right.$ and $2 \mathrm{PO}_{4}$ tetrahedra $)$ and pseudo-4-rings $\left(1 \mathrm{AlO}_{4}, 2 \mathrm{PO}_{4}\right.$ and 1 bridging $\mathrm{H}$ between two terminal $\mathrm{O}$ atoms).

Further experimental confirmation for the occurrence of this type of $\mathrm{AlP}_{2} \mathrm{O}_{8} \mathrm{H}$ chain configuration with the proton attached to $\mathrm{O} 8$ is provided by the comparison of the $\mathrm{P}-\mathrm{O}$ (terminal) distances (which are the most influenced by the $\mathrm{H}$ location) observed experimentally (Table 1) with those of the geometryoptimized (CASTEP) systems with the proton attached to the different terminal $\mathrm{O}$ atoms (Table S9). These results show clearly that the experimental structure is very similar to the calculated one with the proton attached to O8.

\section{E) DFT+D: Theoretical NMR}

DFT calculations and ${ }^{13} \mathrm{C}$ NMR show that the two DPG molecules present in the ICP-1 unit cell should be protonated. However, two different signals for the guanidinium $\mathrm{C}$ atoms appear in the ${ }^{13} \mathrm{C}$ NMR spectrum of ICP-1 (Figure $4 d$ ). In order to clarify this, we calculated the theoretical ${ }^{13} \mathrm{C} N \mathrm{NMR}$ spectrum of ICP-1 using the CASTEP methodology. Theoretical results showed two different signals for the guanidinium $\mathrm{C}$ atom, each associated with one of the two different conformations present in the structure. The signals differ by $\sim 5 \mathrm{ppm}$, which is very similar to the experimental ${ }^{13} \mathrm{C}$ NMR results. The high-field resonance $(152 \mathrm{ppm})$ is from the conformation where the two aromatic rings of DPG are close to each other (DPG-1 in Figure 6c), which corresponds to the conformer A in section A (Figure 1), and the low-field resonance (157 ppm) 
comes from DPG-2 (Figure 6c), which is similar to conformer $\mathrm{B}$ in section A (Figure 1). The large difference in ${ }^{13} \mathrm{C}$ NMR shift might be due to the different spatial configuration of the $\mathrm{N}$ lone pairs in the guanidinium group. In DPG-1 they are all on the same side, while in DPG-2 one of them is located on the opposite side, thus strongly affecting the chemical environment of the bridging $\mathrm{C}$ atom.

\section{DISCUSSION}

A schematic illustration of the concepts proposed in this study is shown in Figure 9. The tendency of molecules such as diphenylguanidine with clearly distinguishable hydrophilic and hydrophobic regions (Figure 9a), to self-assemble can be exploited to produce very open crystalline aluminophosphate networks. The computational study presented in this work shows that DPG has a strong tendency to form a surfactantlike configuration in water, where the polar guanidinium groups are in close contact with water molecules (Figure 9b), and the hydrophobic aromatic region self-assembles with other DPG molecules to form very large multi-molecular aggregates (Figure 9c). Two regions can be defined: the hydrophobic one, established via $\pi-\pi$ interactions between the aromatic rings in the centre of aggregates, and the hydrophilic one, on the external surface of the aggregates. The latter is governed by interactions between the polar guanidinium groups and the water molecules.

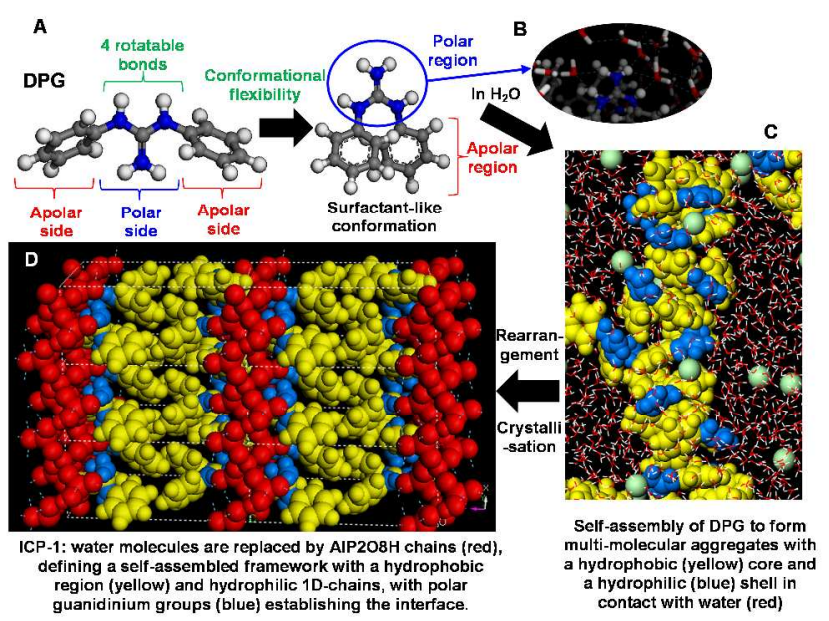

Figure 9. A schematic diagram of the concepts of the selfassembly process proposed. (a) The DPG molecule showing its exploitable features, (b) the interaction between the polar group and water in the surfactant-like conformation, (c) the self-assembly of DPG in water, and (d) the ICP-1 structure. B and $\mathrm{C}$ correspond to $\mathrm{MD}$ snapshots at $\mathrm{t}=1000.0 \mathrm{ps}$.

Because of the size and shape of these aggregates, a lowdimensional AlPO network, rather than a 3D-connected AlPO framework, has been produced. In this way, the structure of ICP-1 is able to accommodate a very large amount of the organic material (Figure 9d). While the $\mathrm{AlP}_{2} \mathrm{O}_{8} 1 \mathrm{D}$ chains are connected to one another through $\mathrm{H}$-bonds with the organic species along the $b$ axis, they are separated by $11 \AA$ along the $c$ axis. Indeed, to the best of our knowledge, ICP-1 represents the synthetic aluminophosphate of known structure (excluding intercalation compounds) with the largest organic content. The amount is comparable to that found in mesoporous materials such as MCM-41. Indeed, its "framework" density is only 4.1 $\mathrm{T} / 1000 \AA^{3}$, much lower than that of the most-open zeolite framework found to date (the mesoporous ITQ-37 zeolite, with a framework density of $\left.10.3 \mathrm{~T} / 1000 \AA^{3}\right){ }^{23}$ However, such a comparison should be taken with care since ICP-1 is not a 3D-framework with a full $\mathrm{T}-\mathrm{O}-\mathrm{T}$ condensation as required for a porous material to be considered a zeolitic framework. In fact, potential applications of ICP-1 are rather limited because of its $1 \mathrm{D}$ nature, which causes the structure to collapse upon elimination of the organic molecules (Figure S2 in the Supporting Information). Nevertheless, it constitutes a proof-of-concept of the potential of using self-assembling molecules to direct the crystallization of very-open frameworks. In addition, it is also remarkable that, although not constituting a unique example, low-dimensional frameworks are commonly obtained under solvothermal (rather than hydrothermal) conditions.

The ICP-1 structure contains one of the fundamental AlPO chains, the AlPO-CSC chain, ${ }^{9}$ which occurs in many aluminophosphate structures. ${ }^{55-59}$ Indeed, many different AlPO frameworks can be constructed from combinations of these chains. ${ }^{60}$ They seem to play a pivotal role in the crystallization of nanoporous aluminophosphates.

The very large amount of ordered DPG in the structure implies that the DPG molecules play a structural role in the formation of the phase, developing an extensive H-bonding network between the $\mathrm{H}(\mathrm{N})$ atoms of $\mathrm{DPG}$ and the terminal $\mathrm{P}-\mathrm{OH}$ and $\mathrm{P}-\mathrm{O}$ groups. DPG-1 forms $\mathrm{H}-$ bonds with different AlPO chains, thus providing a structural connection between the independent $\mathrm{AlP}_{2} \mathrm{O}_{8}$ chains (see Figure $7 \mathrm{a}$ ). On the other hand, DPG-2 establishes $\mathrm{H}$-bonds within a single AlPO chain (Figure $7 b$ ), thus stabilizing the chain and enhancing its rigidity. ${ }^{56}$

It is important to note the relationship between the position of the $\mathrm{O}\left(\mathrm{H}_{2} \mathrm{O}\right)$ atoms found in the MD simulations in water and the terminal $\mathrm{O}$ atoms in ICP-1 (Figure S4 in the Supporting Information). They are located at very similar distances from the polar guanidinium groups of DPG, establishing $\mathrm{H}$-bonds with the $\mathrm{H}(\mathrm{N})$ atoms (red and blue lines). As might be expected, the aromatic $\mathrm{H}$ atoms do not interact at all with the AlPO chain, but are located in the centre of the aggregates, as was the case with the multi-molecular aggregates in water (Figure S4, green lines). There is a clear structural relationship between the multi-molecular DPG aggregates in water and those found in the ICP-1 structure (Figure 9c and d), suggesting that the hydrophilic aluminophosphate $\mathrm{P}-\mathrm{O}(\mathrm{H})$ species occupy the positions of the water molecules to produce the hybrid DPG-AlPO structure.

Finally, the possible implications of this study for the crystallization of 3D nanoporous frameworks need to be considered. Our results show that a complex network of H-bonds between the $\mathrm{H}(\mathrm{N})$ atoms of the polar guanidinium groups of DPG and the terminal $\mathrm{P}-\mathrm{O}$ groups of an AlPO chain forms. These $\mathrm{H}(\mathrm{N})$ atoms tend to interact with terminal $\mathrm{P}-\mathrm{O}$ groups to form low-dimensional structures. A potential synthesis route to $3 \mathrm{D}$ frameworks would be to replace these $\mathrm{H}(\mathrm{N})$ atoms with other organic groups (e.g. alkyl substituents), but to retain the self-assembly tendency of the molecule. In this way, perhaps the strong interaction with the terminal $\mathrm{O}$ atoms could be reduced so that the chain can condense into a very open framework structure.

\section{CONCLUSIONS}

Diphenylguanidine (DPG) has been used as structure-directing agent for the synthesis of an aluminophosphate structure. The selection of this molecule was rational and based on (1) the presence of distinguishable hydrophilic (guanidine) and hy- 
drophobic (aromatic) groups, (2) the self-aggregation behavior through $\pi-\pi$ type interactions, and (3) the high conformational flexibility. Molecular mechanics-based simulations show clearly that the synergy of these three features drives the molecule to form very large multi-molecular aggregates in water. These large structure-directing entities have a hydrophobic core occupied by the aromatic rings, and an external shell of guanidine moieties in close contact with water molecules.

Indeed, ICP-1, a 1D aluminophosphate structure with an extremely large organic content, which is more typical of mesoporous materials, has been obtained. The structure is composed of $1 \mathrm{D} \mathrm{AlP} \mathrm{O}_{2} \mathrm{H}$ chains with organic molecules between them. Abundant $\pi-\pi$ type interactions between the aromatic rings are established in the interchain region, forming very large supramolecular aggregates. Polar guanidinium groups establish a complex $\mathrm{H}$-bond network with the terminal $\mathrm{P}-\mathrm{O}$ groups of the AlPO chain, and these sustain the whole architecture. The result is an open framework material with a very low "framework" density, and with highly hydrophobic regions.

\section{ACKNOWLEDGMENTS}

The research leading to these results has received funding from the Spanish Ministry of Science and Innovation MICINN (projects MAT2009-13569 and MAT2012-31127) and the European Research Council, under the Marie Curie Career Integration Grant program (FP7-PEOPLE-2011-CIG), Grant Agreement PCIG09-GA-2011-291877. L.G.-H. acknowledges the Spanish Ministry of Education and Science for a Juan de la Cierva contract. A.B.P. acknowledges the support of the European Community under a Marie Curie Intra-European Fellowship for Career Development. The authors thank the beamline scientists at the SNBL at the ESRF in Grenoble, France for their assistance with the powder diffraction measurement, and Dr. Dmitry Logvinovich at the Laboratory of Crystallography, ETH Zürich for his help with the single crystal diffraction measurement. Dr Lynne B. McCusker's guidance on the Rietveld refinement and critical revision of the manuscript is deeply acknowledged. Accelrys is acknowledged for providing the computational software, and Centro Técnico de Informática-CSIC for running the calculations.

\section{ASSOCIATED CONTENT}

\section{Supporting Information.}

The crystallographic information file (CIF) corresponding to ICP1 , additional crystallographic and synthesis information. "This material is available free of charge via the Internet at http://pubs.acs.org."

\section{AUTHOR INFORMATION}

\section{Corresponding Author}

Luis Gómez-Hortigüela

lhortiguela@icp.csic.es

Instituto de Catálisis y Petroleoquímica (CSIC)

Marie Curie 2, 28049, Cantoblanco, Madrid (Spain)

Telephone: +34-91-5854785; Fax: +34-91-5854760.

\section{TABLE OF CONTENTS}




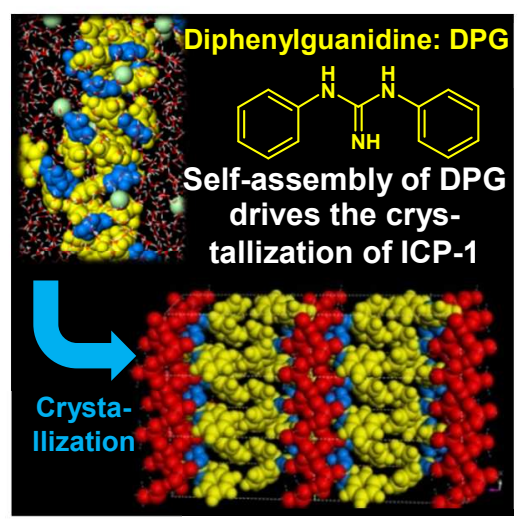

\section{REFERENCES}

(1) d'Yvoire, F. Etude des phosphates d'aluminium et de fer trivalent. I. L'orthophosphate neutre d'aluminium. Bull. Soc. Chim. France 1961, 1961, 1762-1776.

(2) Wilson, S. T.; Lok, B. M.; Flanigen, E. M. Crystalline metallophosphate compositions. U.S. Patent 4310440, 1982. 
(3) Szostak, R. Molecular Sieves, Principles of Synthesis and Identification. Blackie Academic \& Professional, London, 1998; pp. 251-277.

(4) Flanigen, E. M.; Patton R. L.; Wilson, S. T. Structural, Synthetic and Physicochemical Concepts in Molecular Sieves. Stud. Surf. Sci. Catal. 1988, 37, 13-27.

(5) Wilson, S. T. Synthesis of $\mathrm{AlPO}_{4}$-Based Molecular Sieves. Stud. Surf. Sci. Catal. 1991, 58, 137-151.

(6) Wilson, S. T. Phosphate-Based Molecular Sieves: Novel Synthetic Approaches to New Structures and Compositions. Stud. Surf. Sci. Catal. 2001, 137, 229-260.

(7) Livage, J. Sol-Gel Chemistry and Molecular Sieve Synthesis. Stud. Surf. Sci. Catal. 1994, 85, 1-42.

(8) Xing, H.; Li, J.; Yan, W.; Chen, P.; Jin, Z.; Yu, J.; Dai, S.; $\mathrm{Xu}$. R. Cotemplating Ionothermal Synthesis of a New OpenFramework Aluminophosphate with Unique Al/P Ratio of 6/7. Chem. Mater. 2008, 20, 4179-4181.

(9) $\mathrm{Yu}, \mathrm{J} . ; \mathrm{Xu}, \mathrm{R}$. Rich Structure Chemistry in the Aluminophosphate Family. Acc. Chem. Res. 2003, 36, 481-490.

(10) Huo, Q.; Xu, R.; Li, S.; Ma, Z.; Thomas, J. M.; Jones, R. H.; Chippindale, A. M. Synthesis and Characterization of a Novel Extra Large Ring of Aluminophosphate JDF-20. J. Chem. Soc., Chem. Commun. 1992, No 12, 875-876.

(11) Pérez-Pariente, J.; Gómez-Hortigüela L. "The role of templates in the synthesis of zeolites", in Zeolites: From model materials to industrial catalysts; Čejka, J., Peréz-Pariente, J., Roth, W. J. Eds.; Transworld Research Network: Kerala, India, 2008; pp. 33-62.

(12) Cundy, C. S.; Cox, P. A. The Hydrothermal Synthesis of Zeolites: History and Development from the Earliest Days to the Present Time. Chem. Rev. 2003, 103, 663-702.

(13) Davis, M. E.; Lobo, R. F. Zeolite and Molecular-Sieve Synthesis. Chem. Mater. 1992, 4, 756-768.

(14) Rollmann, L. D.; Valyoosik, E. M. Synthesis of zeolite ZSM-11. U.S. Patent 4108881, 1978.

(15) Lawton, S. L.; Rohrbaugh, W. J. The Framework Topology of ZSM-18, a Novel Zeolite Containing Rings of 3 (Si,Al)-O Species. Science 1991, 247, 1319-1322.

(16) Kubota, Y.; Helmkamp, M. M.; Zones, S. I.; Davis, M. E. Properties of Organic Cations that Lead to the StructureDirection of High-Silica Molecular Sieves. Microporous Mater. 1996, 6, 213-229.

(17) Zones, S. I.; Hwang, S.-J.; Elomari, S.; Ogino, I.; Davis, M. E.; Burton, A. W. C. R. The Fluoride-Based Route to AllSilica Molecular Sieves; a Strategy for Synthesis of New Materials Based upon Close-Packing of Guest-Host Products. Chimie 2005, 8, 267-282.

(18) Freyhardt, C. C.; Tsapatsis, M.; Lobo, R. F.; Balkus, K. J.; Davis, M. E. A High-Silica Zeolite with a 14-TetrahedralAtom Pore Opening. Nature 1996, 381, 295-298.

(19) Lobo, R. F.; Tsapatsis, M.; Freyhardt, C. C.; Khodabandeh, S.; Wagner, P.; Chen, C. Y.; Balkus, K. J.; Zones, S. I.; Davis, M. E. Characterization of the Extra-Large-Pore Zeolite UTD-1. J. Am. Chem. Soc. 1997, 119, 8474-8484.

(20) Wessels, T.; Baerlocher, C.; McCusker, L. B.; Creyghton, E. J. An Ordered Form of the Extra-Large-Pore Zeolite UTD1: Synthesis and Structure Analysis from Powder Diffraction Data. J. Am. Chem. Soc. 1999, 121, 6242-6247.
(21) Wagner, P.; Yoshikawa, M.; Lovallo, M.; Tsuji, K.; Tsapatsis, M.; Davis, M. E. CIT-5: A High-Silica Zeolite with 14-Ring Pores. Chem. Commun. 1997, No 22, 2179-2180.

(22) Yoshikawa, M.; Wagner, P.; Lovallo, M.; Tsuji, K.; Takewaki, T.; Chen, C. Y.; Beck, L. W.; Jones, C.; Tsapatsis, M.; Zones, S. I. et al.. Synthesis, Characterization, and Structure Solution of CIT-5, a New, High-Silica, Extra-Large-Pore Molecular Sieve. J. Phys. Chem. B 1998, 102, 7139-7147.

(23) Sun, J.; Bonneau, C.; Cantín, A.; Corma, A.; DíazCabañas, M. J.; Moliner, M.; Zhang, D.; Li, M.; Zou, X. The ITQ-37 Mesoporous Chiral Zeolite. Nature 2009, 458, 11541157.

(24) Martinez-Franco, R.; Moliner, M.; Yun, Y. F.; Sun, J. L.; Wan, W.; Zou, X. D.; Corma, A. Synthesis of an Extra-Large Molecular Sieve Using Proton Sponges as Organic StructureDirecting Agents. Proc. Natl. Acad. Sci. USA 2013, 110, 3749-3754.

(25) Moliner, M.; Willhammar, T.; Wan, W.; Gonzalez, J.; Rey, F.; Jorda, J. L.; Zou, X. D.; Corma, A. Synthesis, Design and Structure of a Multipore Zeolite with Interconnected 12and 10-MR Channels J. Am. Chem. Soc. 2012, 134, 64736478.

(26) Yu, J.; Xu, R. Rational Aproaches Towards the Design and Synthesis of Zeolitic Inorganic Open-Framework Materials. Acc. Chem. Res. 2010, 43, 1195-1204.

(27) Gómez-Hortigüela, L.; Corà, F.; Catlow, C. R. A.; PérezPariente, J. Computational Study of the Structure-Directing Effect of Benzylpyrrolidine and its Fluorinated Derivatives in the Synthesis of the Aluminophosphate AlPO-5. J. Am. Chem. Soc. 2004, 126, 12097-12102.

(28) Gómez-Hortigüela, L.; López-Arbeloa, F.; Corà, F.; Pérez-Pariente, J. Supramolecular Chemistry in the Structure Direction of Microporous Materials from Aromatic StructureDirecting Agents. J. Am. Chem. Soc. 2008, 130, 13274 13284.

(29) Gómez-Hortigüela, L.; Pérez-Pariente, J.; López-Arbeloa, F. Aggregation Behavior of (S)-(-)-N-benzylpyrrolidine-2Methanol in the Synthesis of the AFI Structure in the Presence of Dopants. Microporous Mesoporous Mater. 2009, 119, 299305.

(30) Gómez-Hortigüela, L.; Hamad, S.; Pinar, A. B.; LópezArbeloa, F.; Pérez-Pariente, J.; Corà, F. Molecular Insights into the Self-Aggregation of Aromatic Molecules in the Synthesis of Nanoporous Aluminophosphates: a Multilevel Approach. J. Am. Chem. Soc. 2009, 131, 16509-16524.

(31) Gómez-Hortigüela, L.; López-Arbeloa, F.; MárquezÁlvarez, C.; Pérez-Pariente, J. Effect of Fluorine and Molecular Charge-State on the Aggregation Behavior of (S)-(-)-NBenzylpyrrolidine-2-Methanol Confined within the AFI Nanoporous Structure. J. Phys. Chem. C 2013, 117, 8832-8839.

(32) Corma, A.; Rey, F.; Rius, J.; Sabater, M. J.; Valencia, S. Supramolecular Self-Assembled Molecules as Organic Directing Agent for Synthesis of Zeolites. Nature 2004, 431, $287-$ 290.

(33) Wang, J.; Song, J.; Yin, C.; Ji, Y.; Zou, Y.; Xiao, F.-S. Tetramethylguanidine-Templated Synthesis of Aluminophosphate-Based Microporous Crystals with AFI-Type Structure. Microporous Mesoporous Mater. 2009, 117, 561-569.

(34) Dauger-Osguthorpe, P.; Roberts, V. A.; Osguthorpe, D. J.; Wolff, J.; Genest, M.; Hagler, A. T. Structure and Energe- 
tics of Ligand-Binding to Proteins-Escherichia-Coli Dihydrofolate Reductase Trimethoprim, a Drug-Receptor System. Proteins: Struct., Funct., Genet. 1988, 4, 31-47.

(35) Williams, J. J.; Smith, C. W.; Evans, K. E.; Lethbridge, Z. A. D.; Walton, R. I. Off-Axis Elastic Properties and the Effect of Extraframework Species on Structural Flexibility of the NAT-Type Zeolites: Simulations of Structure and Elastic Properties. Chem. Mater. 2007, 19, 2423-2434.

(36) Rojas, A.; Gómez-Hortigüela, L.; Camblor, M. Benzylimidazolium Cations as Zeolite Structure-Directing Agents. Dalton Trans. 2013, 42, 2562-2571.

(37) Conformer Calculation module, Material Studio, version 6.1, Accelrys Inc., San Diego, CA, 2012.

(38) Discover module, Material Studio, version 6.1, Accelrys Inc., San Diego, CA, 2012.

(39) CrysAlysPro, version 1.171.34.49, Oxford Diffraction Ltd, Abingdon, England, 2006.

(40) Farrugia, L. J. WinGX and ORTEP for Windows: an Update. J. Appl. Cryst. 2012, 45, 849-854.

(41) Sheldrick, G. M. A Short History of SHELX. Acta Cryst. 2008, A64, 112-122.

(42) Baerlocher, C. The X-Ray Rietveld System (XRS-82), a set of computer programs for the Rietveld refinement of X-ray powder data, Institut für Kristallographie, ETH, Zürich, Switzerland 1982.

(43) CrystalMaker: a crystal and molecular structures program for Mac and Windows. CrystalMaker Software Ltd, Oxford, England (www.crystalmaker.com).

(44)Graesslin, J. Exploiting the Mythen-II detector system in the texture method to determine the structures of polycrystalline materials, Ph.D. Thesis, ETH Zurich, Zurich, March 2013.

(45) Perdew, J. P.; Burke, K.; Ernzerhof, M. Generalized Gradient Approximation Made Simple. Phys. Rev. Lett. 1996, 77, 3865-3868.

(46) Delley, B. From Molecules to Solids with the DMol3 Approach. J. Chem. Phys. 2000, 113, 7756-7764.

(47) DMol3 module, Material Studio, version 6.1, Accelrys Inc., San Diego, CA, 2012.

(48) Grimme, S. Semiempirical GGA-Type Density Functional Constructed with a Long-Range Dispersion Correction. $J$. Comput. Chem. 2006, 27, 1787-1799.

(49) Clark, S. J.; Segall, M. D.; Pickard, C. J.; Hasnip, P. J.; Probert, M. J.; Refson, K.; Payne, M. C. Z. First Principles Methods Using CASTEP. Kristallogr. 2005, 220, 567-570.

(50) CASTEP Module, Material Studio, version 6.1, Accelrys Inc., San Diego, CA, 2012.

(51) Profeta, M.; Mauri, F.; Pickard, C. J. Accurate First Principles Prediction of O-17 NMR Parameters in $\mathrm{SiO}_{2}$ : Assignment of the Zeolite Ferrierite Spectrum. J. Am. Chem. Soc. 2003, 125, 541-548.

(52) Vaughan, D. E. W.; Yennawar, H. P.; Perrota, A. J. Synthesis and Structure of a 3D Aluminophosphate (PSU-3). Microporous Mesoporous Mater. 2012, 153, 18-23.

(53) Spek, A. L. Structure Validation in Chemical Crystallography. Acta Cryst. 2009, D65, 148-155.

(54) Macrae, C. F.; Edgington, P. R.; McCabe, P.; Pidcock, E.; Shields, G. P.; Taylor, R.; Towler, M.; van de Streek, J. Mercury: Visualization and Analysis of Crystal Structures. J. Appl. Cryst. 2006, 39, 453-457.
(55) Yu, J.; Xu, R.; Li, J. Structural Diversity of a Family of Aluminophosphates with Al/P Ratio of Non-Unity. Sol. Sta. Sci. 2000, 2, 181-192.

(56) Jones, R. H.; Thomas, J. M.; Xu, R.; Huo, Q.; Xu, Y.; Cheetham, A. K.; Bieber, D. Synthesis and Structure of a OneDimensionally Extended Aluminium Phosphate: $\mathrm{Et}_{3} \mathrm{NH}^{+}\left(\mathrm{H}_{2} \mathrm{AlP}_{2} \mathrm{O}_{8}\right)$. J. Chem. Soc. Chem. Commun. 1990, No. 17, 1170-1172.

(57) Ayi, A. A.; Choudhury, A.; Natarajan, S. Linear-Chain AlPOs Obtained by the Reaction of Amine Phosphates with $\mathrm{Al}^{3+}$ Ions. J. Sol. Sta. Chem. 2001, 156, 185-193.

(58) Wang, K.; Yu, J.; Li, C.; Xu, R. Investigation of Chainto-Chain and Chain-to-Open-Framework Transformations of Two One-Dimensional Aluminophosphate Chains. Inorg. Chem. 2003, 42, 4597-4602.

(59) Chen, P.; Li, J.; Yu, J.; Wang, Y.; Pan, Q.; Xu, R. The Synthesis and Structure of a Chiral 1D Aluminophosphate Chain Compound: D-Co(en $)_{3}\left[\mathrm{AlP}_{2} \mathrm{O}_{8}\right] \cdot 6.5 \mathrm{H}_{2} \mathrm{O}$. J. Sol. Sta. Chem. 2005, 178, 1929-1934.

(60) Oliver, S.; Kuperman, A. Ozin, G. A. A New Model for Aluminophosphate Formation: Transformation of a Linear Chain Aluminophosphate to Chain, Layer, and Framework Structures. Angew. Chem. Int. Ed. 1998, 37, 46-62. 
Synthesis of the Aluminophosphate ICP-1 by Self-Assembly of 1,3-Diphenylguanidine: Insights into Supramolecular

\section{Aggregation}

Teresa Álvaro-Muñoz $z^{\dagger}$ Ana B. Pinar ${ }^{\ddagger}$, Dubravka Šiša $k^{\ddagger}$, Joaquín Pérez-Pariente ${ }^{\dagger}$ and Luis Gómez-Hortigüela ${ }^{\dagger} *$

\footnotetext{
${ }^{\dagger}$ Instituto de Catálisis y Petroleoquímica, ICP-CSIC. C/ Marie Curie 2, 28049. Madrid, Spain.
}

ॠ Laboratory of Crystallography, ETH Zurich, CH-8093 Zurich, Zurich, Switzerland.

\section{Supporting Information}


Table S1. Gel composition and synthesis conditions $x$ DPG: $1 \mathrm{Al}_{2} \mathrm{O}_{3}: 1 \mathrm{P}_{2} \mathrm{O}_{5}: 110 \mathrm{H}_{2} 0$

(Samples A-X-T) that led to ICP-1. PD: intermediate product resulting of DPG decomposition.

\begin{tabular}{cccccccc}
\hline & & & & \multicolumn{5}{c}{ Time / Phase } \\
\cline { 6 - 8 } Sample & $\mathbf{x}$ & $\mathbf{p H}$ & $\mathbf{T}$ & $\mathbf{1 ~ h}$ & $\mathbf{3 ~ h}$ & $\mathbf{1 ~ d}$ & $\mathbf{4 ~ d}$ \\
\hline $\mathbf{A - 1 . 5 - 1 0 0}$ & 1.5 & 4.55 & 100 & - & ICP-1 & ICP-1 & ICP-1 \\
$\mathbf{A - 1 . 5 - 1 3 0}$ & 1.5 & 4.55 & 130 & - & ICP-1 & ICP-1 & ICP-1 + PD \\
$\mathbf{A - 1 . 5 - 1 5 0}$ & 1.5 & 4.55 & 150 & ICP-1 & ICP-1 & ICP-1 + PD & PD + AlPO-15 \\
$\mathbf{A - 1 . 5 - 1 8 0}$ & 1.5 & 4.55 & 180 & ICP-1 & ICP-1 + PD & ICP-1 + PD & - \\
\hline $\mathbf{A - 2 - 1 0 0}$ & 2 & 4.93 & 100 & - & ICP-1 & ICP-1 & ICP-1 \\
$\mathbf{A - 2 - 1 3 0}$ & 2 & 4.93 & 130 & - & ICP-1 & PD & PD + AlPO-15 \\
$\mathbf{A - 2 - 1 5 0}$ & 2 & 4.93 & 150 & - & ICP-1 & PD + AlPO-15 & AlPO-15 \\
\hline
\end{tabular}

Table S2. Single crystal X-ray diffraction data collection for ICP-1.

\begin{tabular}{ll}
\hline Instrument & $\mathrm{X}^{\prime}$ Calibur Onyx, AGILENT \\
Wavelength & $\mathrm{MoK}_{\alpha}(0.7107 \AA)$ \\
Monochromator & Graphite \\
Detector & CCD Onyx \\
Collimator & 0.5 \\
Sample & Thin plates, white \\
$2 \theta$ measured & $4.0820-29.6665$ \\
Absorption correction type & Multi scan \\
\hline
\end{tabular}

Table S3. Powder diffraction data collection parameters for ICP-1.

\begin{tabular}{lr}
\hline Synchrotron facility & SNBL (BM01B) at ESRF \\
Wavelength & $0.5035 \AA$ \\
Diffraction geometry & Debye-Scherrer \\
Analyzer crystal & Si 111 \\
Sample & Rotating $1.0 \mathrm{~mm}$ capillary \\
$2 \theta$ range measured & $0.5-39.4^{\circ}$ \\
$2 \theta$ range used for refinement & $2.5-36.7^{\circ}$ \\
Step size & $0.0025^{\circ} 2 \theta$ \\
\hline
\end{tabular}


Table S4. Results of the structure refinement in $P 1$ symmetry.

\begin{tabular}{|c|c|}
\hline No. Reflections measured & 171338 \\
\hline No. Inconsistent equivalents & 62 \\
\hline No. Unique reflections & 15141 \\
\hline$R$ (int) & 0.2754 \\
\hline$R$ (sigma) & 0.2663 \\
\hline $\mathrm{Fo}>4 \sigma \mathrm{Fo}$ & 5526 \\
\hline$w R($ all $)$ & 0.3752 \\
\hline$R_{1}$ (observed reflections) & 0.0913 \\
\hline$R_{1}$ (all reflections) & 0.3008 \\
\hline Goodness of fit $(G O F=S)$ & 1.1410 \\
\hline$\Delta \rho_{\max }\left(\mathrm{e} \AA^{3}\right)$ & 2.11 \\
\hline$\Delta \rho_{\max }\left(\mathrm{e}^{3}\right)$ & -0.42 \\
\hline
\end{tabular}

Table S5. Results of the structure refinement in $P \overline{1}$.

\begin{tabular}{ll}
\hline No. Reflections measured & 171338 \\
No. Inconsistent equivalents & 12 \\
No. Unique reflections & 5539 \\
$R($ int $)$ & 0.2375 \\
$R($ sigma $)$ & 0.0889 \\
Fo $>4$ Fo & 2919 \\
$w R($ all $)$ & 0.223 \\
$w R$ (observed) & 0.186 \\
$R_{1}$ (observed reflections $)$ & 0.078 \\
$R_{1}$ (all reflections) & 0.148 \\
Goodness of fit $(G O F=S)$ & 0.984 \\
$\Delta \rho_{\max }\left(\mathrm{e} \AA^{3}\right)$ & 1.002 \\
$\Delta \rho_{\max }\left(\AA^{3}\right)$ & -0.38 \\
\hline
\end{tabular}


Table S6. Crystallographic data from the Rietveld refinement of ICP-1. ${ }^{a}$

\begin{tabular}{|c|c|c|}
\hline Chemical composition & & $\left|\mathrm{C}_{52} \mathrm{~N}_{12} \mathrm{H}_{56}\right|_{4}\left[\mathrm{Al}_{2} \mathrm{P}_{4} \mathrm{O}_{16}\right]$ \\
\hline \multicolumn{3}{|l|}{ Unit cell } \\
\hline$a$ & & $7.668(22) \AA$ \\
\hline$b$ & & $10.717(33) \AA$ \\
\hline$c$ & & $18.581(14) \AA$ \\
\hline$\alpha$ & & $88.9(1.3)^{\circ}$ \\
\hline$\beta$ & & $88.2(2.3)^{\circ}$ \\
\hline$\gamma$ & & $74.2(2.9)^{\circ}$ \\
\hline \multicolumn{2}{|l|}{ Space Group } & $P \overline{1}$ \\
\hline \multicolumn{2}{|l|}{ Standard peak $(h k l, 2 \theta)$} & $212,16.10^{\circ}$ \\
\hline \multicolumn{2}{|l|}{ Peak range (FWHM) } & 15 \\
\hline \multicolumn{2}{|l|}{ Data points } & 5314 \\
\hline \multicolumn{2}{|l|}{ Contributing reflections } & 735 \\
\hline \multicolumn{2}{|l|}{ Geometric restraints ${ }^{\mathrm{b}}$} & 88 \\
\hline $\mathrm{P}-\mathrm{O}$ & $1.52(1) \AA$ & 8 \\
\hline $\mathrm{Al}-\mathrm{O}$ & $1.74(1)^{\circ}$ & 4 \\
\hline $\mathrm{O}-\mathrm{T}-\mathrm{O}^{\mathrm{c}}$ & $109.5(2)^{\circ}$ & 18 \\
\hline $\mathrm{T}-\mathrm{O}-\mathrm{T}^{\mathrm{c}}$ & $145(8)^{\circ}$ & 4 \\
\hline $\mathrm{C}-\mathrm{N}$ & $1.31(1) / 1.41(1) \AA$ & 10 \\
\hline $\mathrm{C}-\mathrm{C}$ & $1.35(1)-1.39(1) \AA$ & 24 \\
\hline $\mathrm{N}-\mathrm{C}-\mathrm{N}$ & $120.0(8)^{\circ}$ & 4 \\
\hline $\mathrm{C}-\mathrm{N}-\mathrm{C}$ & $125.1(8)-129.0(8)^{\circ}$ & 4 \\
\hline $\mathrm{C}-\mathrm{C}-\mathrm{C}$ & $120.0(8)^{\circ}$ & 12 \\
\hline \multicolumn{3}{|l|}{ Parameters } \\
\hline \multicolumn{2}{|l|}{ structural } & 130 \\
\hline \multicolumn{2}{|l|}{ profile } & 9 \\
\hline \multicolumn{2}{|l|}{$R_{F}$} & 0.109 \\
\hline \multicolumn{2}{|l|}{$R_{w p}$} & 0.334 \\
\hline \multicolumn{2}{|l|}{$R_{\exp }$} & 0.288 \\
\hline
\end{tabular}

${ }^{a}$ The numbers given in parentheses are the esd's in the units of the least significant digit.

Each restraint was given a weight equivalent to the reciprocal of its esd.

${ }^{b}$ The geometric restraints were removed at the end of the refinement.

${ }^{c} \mathrm{~T}$ refers to $\mathrm{Al}$ and $\mathrm{P}$. 
Table S7. Selected interatomic distances $(\AA)$ and angles $\left({ }^{\circ}\right)$ for the organic DPG molecules within ICP-1, and $\mathrm{H}$-bond distances with the AlPO oxygen atoms.

\begin{tabular}{cccc} 
DPG-1 & \multicolumn{3}{c}{ DPG-2 } \\
\hline Distances $(\AA)$ & & $\mathrm{N} 11-\mathrm{C} 111$ & 1.32 \\
$\mathrm{~N} 1-\mathrm{C} 1$ & 1.32 & $\mathrm{~N} 12-\mathrm{C} 111$ & 1.34 \\
$\mathrm{~N} 2-\mathrm{C} 1$ & 1.36 & $\mathrm{~N} 12-\mathrm{C} 112$ & 1.44 \\
$\mathrm{~N} 2-\mathrm{C} 2$ & 1.42 & $\mathrm{~N} 13-\mathrm{C} 111$ & 1.35 \\
$\mathrm{~N} 3-\mathrm{C} 1$ & 1.35 & $\mathrm{~N} 13-\mathrm{C} 118$ & 1.42 \\
$\mathrm{~N} 3-\mathrm{C} 8$ & 1.42 & 1.37 \\
$\mathrm{C}-\mathrm{C}$ arom avg & 1.37 & & \\
Angles $\left(^{\circ}\right)$ & & & 119.70 \\
$\mathrm{~N} 1-\mathrm{C} 1-\mathrm{N} 3$ & 116.40 & $\mathrm{~N} 11-\mathrm{C} 11-\mathrm{N} 13$ & 119.30 \\
$\mathrm{~N} 1-\mathrm{C} 1-\mathrm{N} 2$ & 117.30 & $\mathrm{~N} 11-\mathrm{C} 111-\mathrm{N} 12$ & 125.00 \\
$\mathrm{C} 1-\mathrm{N} 3-\mathrm{C} 8$ & 127.90 & $\mathrm{C} 111-\mathrm{N} 13-\mathrm{C} 118$ & 127.80 \\
$\mathrm{C} 1-\mathrm{N} 2-\mathrm{C} 2$ & 128.90 & $\mathrm{C} 111-\mathrm{N} 12-\mathrm{C} 112$ & 119.90 \\
$\mathrm{C}-\mathrm{C}-\mathrm{C}$ arom avg & 119.90 & & 3.13 \\
\hline H-bonds & & & 3.17 \\
$\mathrm{~N} 1-\mathrm{O} 2$ & 3.04 & $\mathrm{~N} 11-\mathrm{O} 3$ & 2.94 \\
$\mathrm{~N} 1-\mathrm{O} 8$ & 3.13 & $\mathrm{~N} 11-\mathrm{O} 7$ & 2.81 \\
$\mathrm{~N} 2-\mathrm{O} 7$ & 2.92 & $\mathrm{~N} 12-\mathrm{O} 2$ \\
$\mathrm{~N} 3-\mathrm{O} 3$ & 2.78 & $\mathrm{~N} 13-\mathrm{O} 3$ & 3.17 \\
\hline
\end{tabular}


Table S8. Atomic coordinates for the structure ICP-1 $1^{\mathrm{a}, \mathrm{b}, \mathrm{c}}$.

\begin{tabular}{|c|c|c|c|}
\hline Atom/site & $x$ & $y$ & $z$ \\
\hline Al1 & $0.782(2)$ & $0.932(1)$ & $0.005(1)$ \\
\hline $\mathrm{P} 1$ & $0.867(2)$ & $0.157(1)$ & $0.922(1)$ \\
\hline $\mathrm{P} 2$ & $0.505(2)$ & $0.162(1)$ & $0.079(1)$ \\
\hline $\mathrm{O} 1$ & $0.853(3)$ & $0.019(2)$ & $0.935(1)$ \\
\hline $\mathrm{O} 2$ & $0.696(3)$ & $0.253(2)$ & $0.952(2)$ \\
\hline $\mathrm{O} 3$ & $0.887(4)$ & $0.180(3)$ & $0.842(1)$ \\
\hline $\mathrm{O} 4$ & $0.032(2)$ & $0.178(2)$ & $0.959(1)$ \\
\hline O5 & $0.333(3)$ & $0.960(2)$ & $0.929(1)$ \\
\hline O6 & $0.361(3)$ & $0.153(2)$ & $0.027(1)$ \\
\hline O7 & $0.422(4)$ & $0.166(3)$ & $0.155(1)$ \\
\hline $\mathrm{O} 8$ & $0.567(4)$ & $0.285(2)$ & $0.063(2)$ \\
\hline $\mathrm{C} 1$ & $0.311(6)$ & $0.504(3)$ & $0.218(1)$ \\
\hline $\mathrm{C} 2$ & $0.280(4)$ & $0.360(2)$ & $0.323(1)$ \\
\hline C3 & $0.374(5)$ & $0.240(4)$ & $0.351(2)$ \\
\hline $\mathrm{C} 4$ & $0.297(6)$ & $0.186(4)$ & $0.408(3)$ \\
\hline $\mathrm{C} 5$ & $0.136(7)$ & $0.252(2)$ & $0.439(3)$ \\
\hline C6 & $0.050(6)$ & $0.376(4)$ & $0.415(3)$ \\
\hline $\mathrm{C} 7$ & $0.127(6)$ & $0.432(3)$ & $0.360(2)$ \\
\hline $\mathrm{C} 8$ & $0.328(4)$ & $0.644(3)$ & $0.321(1)$ \\
\hline C9 & $0.478(6)$ & $0.570(3)$ & $0.356(2)$ \\
\hline $\mathrm{C} 10$ & $0.532(6)$ & $0.617(5)$ & $0.418(3)$ \\
\hline $\mathrm{C} 11$ & $0.432(6)$ & $0.730(5)$ & $0.448(2)$ \\
\hline $\mathrm{C} 12$ & $0.269(6)$ & $0.796(4)$ & $0.418(2)$ \\
\hline $\mathrm{C} 13$ & $0.224(5)$ & $0.759(4)$ & $0.352(2)$ \\
\hline C111 & $0.600(3)$ & $0.832(3)$ & $0.191(2)$ \\
\hline C112 & $0.725(6)$ & $0.609(3)$ & $0.142(1)$ \\
\hline $\mathrm{C} 113$ & $0.800(7)$ & $0.549(4)$ & $0.204(1)$ \\
\hline C114 & $0.926(6)$ & $0.429(4)$ & $0.200(2)$ \\
\hline C115 & $0.962(8)$ & $0.366(3)$ & $0.135(2)$ \\
\hline C116 & $0.884(8)$ & $0.426(4)$ & $0.075(2)$ \\
\hline C117 & $0.774(7)$ & $0.549(4)$ & $0.078(1)$ \\
\hline C118 & $0.771(6)$ & $0.932(3)$ & $0.271(1)$ \\
\hline C119 & $0.733(9)$ & $0.895(4)$ & $0.339(2)$ \\
\hline C1110 & $0.754(8)$ & $0.968(5)$ & $0.398(1)$ \\
\hline C1111 & $0.793(9)$ & $0.086(5)$ & $0.386(2)$ \\
\hline C1112 & $0.830(11)$ & $0.122(4)$ & $0.319(2)$ \\
\hline C1113 & $0.826(9)$ & $0.045(4)$ & $0.261(2)$ \\
\hline N1 & $0.312(7)$ & $0.505(4)$ & $0.147(1)$ \\
\hline $\mathrm{N} 2$ & $0.331(6)$ & $0.387(3)$ & $0.251(1)$ \\
\hline N3 & $0.284(7)$ & $0.619(3)$ & $0.250(1)$ \\
\hline N11 & $0.446(4)$ & $0.890(5)$ & $0.224(3)$ \\
\hline N12 & $0.605(2)$ & $0.738(3)$ & $0.144(2)$ \\
\hline N13 & $0.754(4)$ & $0.860(5)$ & $0.210(2)$ \\
\hline
\end{tabular}




\begin{tabular}{cccc} 
H1 & 0.208 & 0.472 & 0.130 \\
H2 & 0.295 & 0.598 & 0.129 \\
H3 & 0.390 & 0.308 & 0.221 \\
H4 & 0.507 & 0.189 & 0.329 \\
H5 & 0.366 & 0.089 & 0.428 \\
H6 & 0.076 & 0.208 & 0.483 \\
H7 & -0.079 & 0.428 & 0.440 \\
H8 & 0.068 & 0.533 & 0.344 \\
H9 & 0.226 & 0.699 & 0.220 \\
H10 & 0.554 & 0.477 & 0.334 \\
H11 & 0.657 & 0.563 & 0.444 \\
H12 & 0.479 & 0.768 & 0.496 \\
H13 & 0.178 & 0.878 & 0.446 \\
H14 & 0.107 & 0.819 & 0.325 \\
H15 & 0.399 & 0.823 & 0.252 \\
H16 & 0.465 & 0.958 & 0.257 \\
H17 & 0.513 & 0.761 & 0.104 \\
H18 & 0.762 & 0.596 & 0.256 \\
H19 & 0.996 & 0.384 & 0.248 \\
H20 & 1.053 & 0.268 & 0.132 \\
H21 & 0.909 & 0.376 & 0.024 \\
H22 & 0.724 & 0.600 & 0.028 \\
H23 & 0.866 & 0.826 & 0.177 \\
H24 & 0.686 & 0.808 & 0.347 \\
H25 & 0.740 & 0.932 & 0.452 \\
H26 & 0.793 & 1.150 & 0.431 \\
H27 & 0.863 & 1.213 & 0.310 \\
H28 & 0.867 & 1.072 & 0.208 \\
H29 & 0.630 & 0.283 & 0.013 \\
\hline
\end{tabular}

${ }^{\mathrm{a}}$ The multiplicity of all atomic positions is 1 .

${ }^{\mathrm{b}}$ The thermal parameters were kept fixed at 0.01 for $\mathrm{Al}$ and $\mathrm{P}, 0.02$ for $\mathrm{O}$ and 0.04 for $\mathrm{C}, \mathrm{N}$ and $\mathrm{H}$.

c: Numbers in parentheses are the standard deviations (esd's) in the units of the least significant digit given. The position of the $\mathrm{H}$ atoms was not refined; they were simply added on calculated positions so that their electrons are in the model. N1 and N11 are assumed to be protonated, and there is a $\mathrm{P}-\mathrm{OH}$ group as discussed in the text (P2-O8-H29). 
Table S9. H-location and relative energies (in $\mathrm{kcal} / \mathrm{mol}$ per $\mathrm{AlP}_{2} \mathrm{O}_{8} \mathrm{H}_{3}: 2 \mathrm{DPG}$ unit) calculated by DFT+D CASTEP methodology and comparison of the experimental and theoretical P-O terminal $_{\text {distances. }}$

\begin{tabular}{|c|c|c|c|c|c|c|c|c|c|}
\hline \multirow[b]{2}{*}{ System } & \multicolumn{3}{|c|}{ H location } & \multirow{2}{*}{$\begin{array}{l}\text { Relative E } \\
\text { (CASTEP) }\end{array}$} & \multicolumn{5}{|c|}{ P-O terminal $_{\text {distances }(\AA)}\left(\right.$ CASTEP $^{\mathrm{a}}$} \\
\hline & 1 & 2 & 3 & & $\begin{array}{c}\text { P2-O8 } \\
1.55^{\mathrm{b}}\end{array}$ & $\begin{array}{c}\text { P2-O7 } \\
1^{1.52^{b}}\end{array}$ & $\begin{array}{c}\text { P1-O3 } \\
1^{1.51}{ }^{b}\end{array}$ & $\begin{array}{c}\text { P1-O2 } \\
\text { 1.52 }^{\mathrm{b}}\end{array}$ & Diff. $^{c}$ \\
\hline 1 & DPG-A & DPG-B & $\mathrm{O} 8$ & 0.0 & 1.568 & 1.500 & 1.519 & 1.537 & 0.001094 \\
\hline 2 & DPG-A & DPG & $\mathrm{O} 7$ & $1^{1}$ & 1.483 & 1.604 & 1.532 & 1.509 & 0.01215 \\
\hline 3 & DPG-A & DPG- & $\mathrm{O} 3$ & 32.5 & 1.499 & 1.533 & 1.639 & 1.484 & 0.020707 \\
\hline 4 & DPG-A & DPG-B & $\mathrm{O} 2$ & Not min* & --- & --- & --- & --- & ---- \\
\hline
\end{tabular}

*indicates that the system was not a minimum on the Potential Energy Surface, and the proton moved to O8; ${ }^{a}: \mathrm{P}-\mathrm{O}$ (terminal) distances in the systems obtained by CASTEP; ${ }^{\mathrm{b}}$ : experimental distances obtained from the structure solution; ${ }^{c}$ : calculated as the sum of the square differences between the four $\mathrm{P}-\mathrm{O}$ distances. 


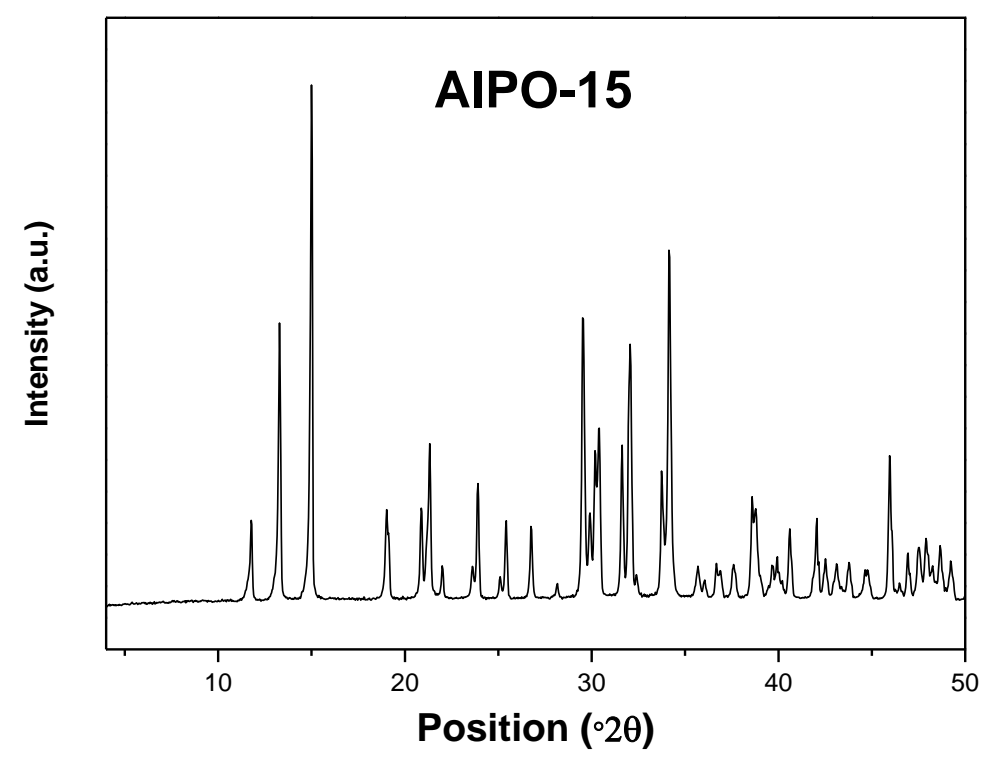

Figure S1. XRD pattern of AlPO-15 (sample A-2-150 at 4 days, see Table S3).

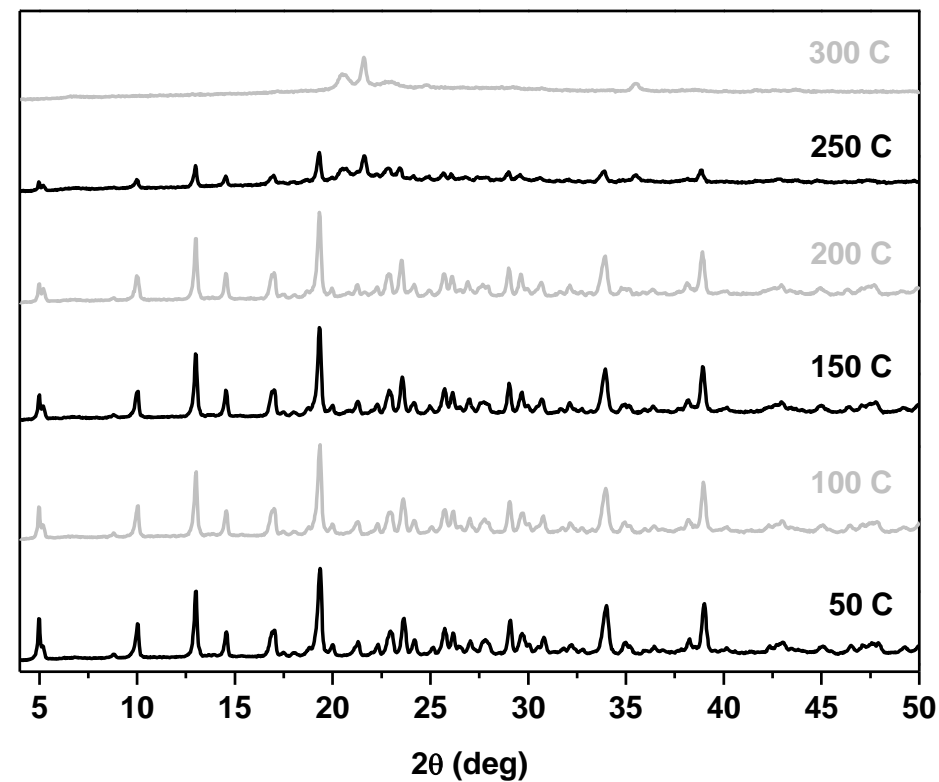

Figure S2. Temperature-programmed XRD experiments of ICP-1. 


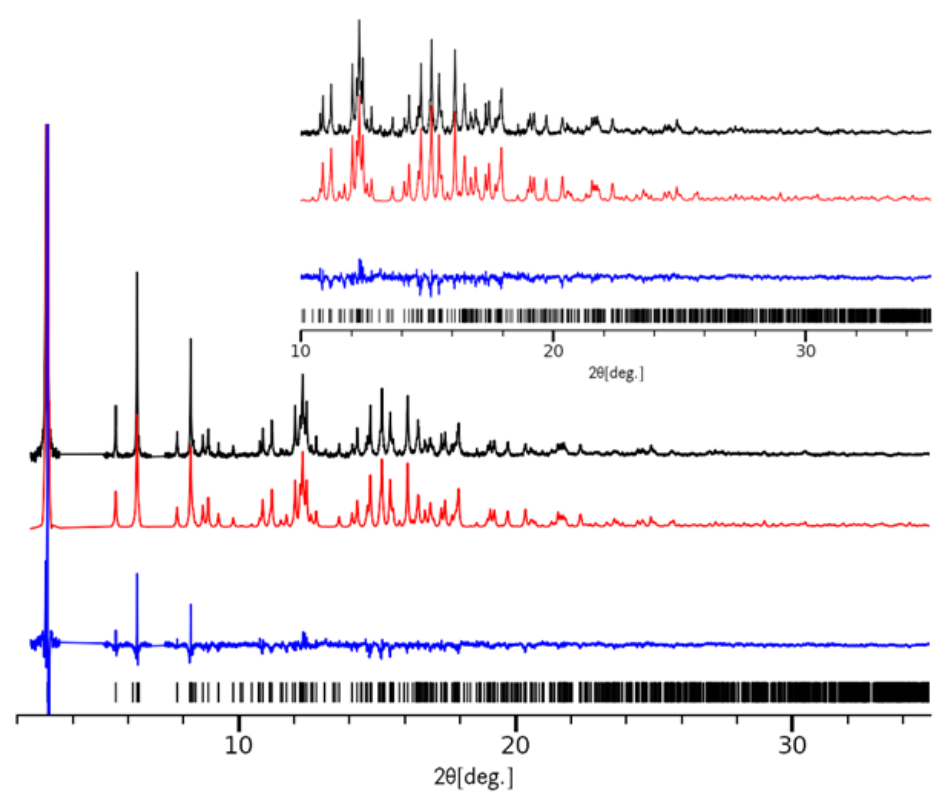

Figure S3. The observed (black), calculated (red) and difference (blue) profiles for the Rietveld refinement of ICP-1. The intensity scale has been cut by a factor of 4 to show more detail at lower angles, and has been reduced by another factor of 2 at higher angles. The tick marks indicate the positions of the reflections. 


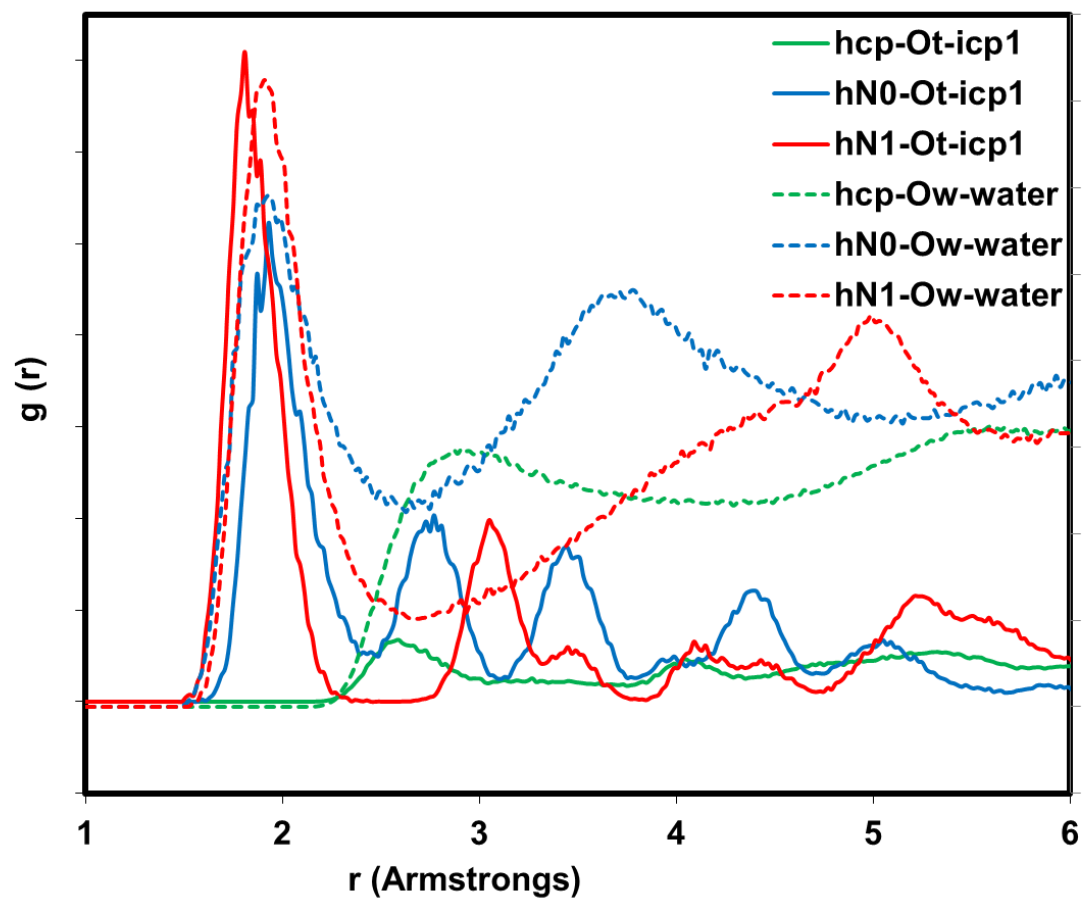

Figure S4. Radial Distribution Functions (RDFs) of an MD simulation (room temperature, keeping the inorganic framework fixed) of $\mathrm{H}$ (bonded to $\mathrm{N}, \mathrm{HN} 0$ and $\mathrm{HN} 1$, and to aromatic C, Hcp) atoms of DPG with terminal O in ICP-1 (solid lines) and water $\mathrm{O}$ in aqueous solution (dashed lines). 